\title{
POLLUTION ABATEMENT AS A SOURCE OF STABILIZATION AND LONG-RUN GROWTH
}

\author{
Theodore Palivos \\ Athens University of Economics and Business \\ Dimitrios VARVARIGOS \\ University of Leicester
}

In a two-period overlapping-generations model with production, we consider the damaging impact of environmental degradation on health and consequently life expectancy. Despite the presence of social constant returns to capital, which would otherwise generate unbounded growth, when pollution is left unabated, the economy cannot achieve such a path. Instead, it converges either to a stationary level of capital per worker or to a cycle in which capital per worker oscillates permanently. The government's involvement in environmental preservation proves crucial for both short-term dynamics and long-term prospects of the economy. Particularly, an active policy of pollution abatement emerges as an important engine of long-run economic growth. Furthermore, by eliminating the occurrence of limit cycles, pollution abatement is also a powerful source of stabilization.

Keywords: Growth, Long-Run Cycles, Environmental Quality, Pollution Abatement

\section{INTRODUCTION}

In recent years, environmental issues have gained prominence in both academic and political discussions. At the same time, they have received considerable media attention. Problems such as the emission of greenhouse gases, the depletion of natural resources, and the presence of hazardous chemicals have become major issues of concern. This is of course not surprising, given their significant direct and indirect repercussions on our health and therefore our overall quality of life.

\footnotetext{
We would like to thank two anonymous referees and an associate editor of this journal, seminar participants at the Université d' Auvergne (Clermond-Ferrand), the Universidad Complutense de Madrid, and the University of Leicester, and participants at the "Conference on Research on Economic Theory and Econometrics" (Tinos 2010), the conference on "Sustainable Growth, Technological Progress and the Environment" (Louvain-la-Neuve 2011), and the workshop in "Advances in Economic Growth" (St Andrews 2011) for comments on earlier drafts of this paper. Address correspondence to: Theodore Palivos, Department of Economics, Athens University of Economics and Business, 76 Patission Str., Athens 10434, Greece; e-mail: tpalivos@ aueb.gr.
} 
Naturally, economic growth has been an indispensable aspect of all the discussion in relation to environmental problems. Given that pollution is a by-product of human activities such as production and consumption, can economies sustain ever-increasing levels of GDP per capita without reaching a tipping point that makes long-run growth environmentally unsustainable? From a different point of view, the preceding discussion has additional implications for the interactions between health indicators and economic growth/development. For example, what are the long-term economic prospects (in terms of capital accumulation) in an economy where environmental degradation has a negative effect on health and life expectancy? Can environmental policy alter these prospects, despite the fact that growth is still detrimental to environmental quality?

To analyze these issues, we build a two-period overlapping-generations model in which pollution affects a person's prospects of survival to the next period ${ }^{1}$ and labor productivity is enhanced by an aggregate learning-by-doing externality. Despite the fact that this type of externality is the source of social constant returns to capital and could potentially allow an equilibrium path with a positive growth rate in the long run, when pollution is left unabated in our model, the economy cannot achieve such a path. Instead, it will converge either to a stationary level of capital per worker (possibly a poverty trap) or to a stable cycle in which capital per worker oscillates permanently. Nevertheless, when resources are devoted to pollution abatement, the equilibrium outcomes change drastically. Specifically, by influencing longevity and saving behavior, public policy (in the form of pollution abatement) can put the economy on a sustainable growth path. Economic growth is environmentally sustainable because a sufficient level of environmental quality is maintained. These outcomes occur even when economic growth has a net damaging effect on environmental quality - with or without environmental policy - and even though the quality of the environment is essential for supporting longevity and therefore saving and capital accumulation. Furthermore, by eliminating long-run cycles, environmental policy smooths income, thereby becoming a source of stabilization, albeit one whose scope and implications are quite different from those of the more conventional countercyclical policies designed against short-term fluctuations.

Our model shares similarities with other studies that have combined elements of environmental quality and health in dynamic economies. Gutiérrez (2008) examines how income taxation can restore dynamic efficiency in an economy where pollution affects the health profile of agents belonging to the old generation. In a similar model, in which agents save more in response to pollution-induced health risk, Wang et al. (2015) demonstrate that an economy may experience high capital accumulation and high pollution levels. They also show how the social optimum can be replicated by a combination of emission taxes on producers, public health spending, and an appropriately designed private health insurance scheme. Balestra and Dottori (2012) examine the politico-economic implications of population aging in a setup where the relative preference weight for environmental care versus direct health expenditures differs between the young and old generations. Using a 
model that accounts for two conflicting health externalities from pollution, Jouvet et al. (2010) show that taxes on both income and private health expenditures are necessary to decentralize the social optimum. Mariani et al. (2010) show that when environmental quality leads to higher life expectancy, the economy may admit multiple, path-dependent equilibria, whereas Varvarigos (2014) shows that such multiplicity also requires the combination of emission taxes with the endogenous choice of environmental technology by producers. Finally, in Pautrel (2008), the natural environment has an amenity value in addition to its beneficial effect on longevity. He shows that greener preferences can support a higher optimal growth rate despite the fact that they are associated with an optimal allocation of time that does not favor human capital accumulation. ${ }^{2}$

These papers account for the two-way causal effects between economic activity and the environment. Our paper differs from these studies in two respects. First, it gives emphasis to the endogenous cycles that arise with respect to output and environmental quality. Hence, it can account for the cyclical interactions between life expectancy and capital accumulation. ${ }^{3}$ Second, the presence of endogenous long-run cycles allows us to explore any scope for pollution abatement as a source not only of growth but also of stabilization.

Naturally, our paper is also related to models of capital accumulation and environmental quality that have identified the possibility of endogenous fluctuations, such as Zhang (1999), Ono (2003), and Seegmuller and Verchère (2004). In terms of setup, the difference of our model from these is threefold. First, we consider the health effects of deteriorating environmental conditions. Second, their mechanisms for endogenous cycles differ from ours. ${ }^{4}$ In our model, cycles may emerge because unbounded environmental degradation and its impact on longevity introduce nonmonotonicity in the dynamics of capital accumulation. Third, we analyze both process-integrated abatement technology, which reduces the economy's emission intensity (i.e., the emission-to-output ratio), and end-of-pipe abatement technology, which reduces the amount of already formed pollutants.

The link between policies of pollution abatement and economic growth is an important element of our results and implications. This link is also analyzed in Bovenberg and Smulders (1995). The authors develop a two-sector representativeagent model with pollution-augmenting technical change and derive technical conditions under which sustainable growth is both feasible and optimal. They then explore optimal environmental policies. Closer to our setting is the analysis of Smulders and Gradus (1996). They use a one-sector growth model in which pollution reduction has a direct benefit to the economy's productivity. They find that pollution abatement allows the economy to sustain growth in the long run. Nevertheless, this is possible only when appropriate parameter restrictions allow abatement to grow at a faster rate compared to pollution. In our model, this type of environmental policy allows the economy to sustain long-run growth despite the fact that the environment is essential for survival and output growth may have a monotonically negative effect on environmental quality, irrespective of whether pollution is abated or not. ${ }^{5}$ 
The rest of the paper is organized as follows. In Section 2 we set up the economic model. In Section 3, we analyze the different equilibrium outcomes of the model, according to whether process-integrated pollution abatement is active or not. In Section 4, we extend our framework to introduce the case where environmental quality is a stock variable. In Section 5, we consider an alternative specification concerning the effect of pollution on health and life expectancy and analyze the effects of end-of-pipe abatement technology. Finally, in Section 6, we summarize our results and draw conclusions.

\section{THE ECONOMIC FRAMEWORK}

We construct an overlapping-generations economy in which time, $t=0,1,2, \ldots$, is measured in discrete intervals that represent periods. The economy is populated by an infinite sequence of agents who face a potential lifetime of two periods. In particular, an agent will live with certainty during the period following her birth, i.e., her youth, but she may or may not survive to her old age. We assume that, before her survival prospect is realized, each agent gives birth to an offspring. Thus, the prospect of untimely death does not have any repercussions for the population mass of newly born agents, whose size we normalize to one.

During youth, each agent is endowed with one unit of labor. She supplies her labor to firms inelastically and receives the competitive wage, $w_{t}$. Even if she survives to maturity, nature does not bestow on her the ability to work when old. For this reason, and in order to satisfy her future consumption needs, she deposits an amount $s_{t}$, when young, with a financial intermediary that promises to repay it next period, augmented by the gross interest rate $r_{t+1}$.

As mentioned earlier, survival to maturity is not certain. We assume that a young person will survive to maturity with probability $\beta_{t} \in[0,1)$, whereas with probability $1-\beta_{t}$ she dies prematurely. Furthermore, we assume that life expectancy is endogenous in the sense that the agent's survival prospect depends on her health characteristics (or health status), denoted as $h_{t}$, according to ${ }^{6}$

$$
\beta_{t}=\mathrm{B}\left(h_{t}\right)
$$

where, following Chakraborty (2004), we assume that $\mathrm{B}^{\prime}\left(h_{t}\right)>0, \mathrm{~B}^{\prime \prime}\left(h_{t}\right)<0$, $\mathrm{B}(0)=0, \mathrm{~B}(\infty)=\lambda, \lambda \in(0,1), \mathrm{B}^{\prime}(0)=\psi, \psi \in(0,1)$, and $\mathrm{B}^{\prime}(\infty)=0$.

We delve further into the determinants of life expectancy by assuming that an agent's health status depends positively on the extent to which the government supports the provision of health services $g_{t}$ (e.g., public hospitals; the presence of a national health system; preventive measures; the design and implementation of health and safety rules) and on the quality of the natural environment $e_{t}$ (e.g., the cleanliness of air, soil, and water; the relative abundance of natural resources such as forestry and other forms of plantation). Formally, these ideas are captured by ${ }^{7}$

$$
h_{t}=g_{t}^{\varphi} e_{t}^{\chi}, \varphi, \chi>0 \text {. }
$$


The assumption that the arguments affecting health status are introduced through a Cobb-Douglas specification is not new [for example, see van Zon and Muysken (2001)]. Obviously, one main reason is the tractability associated with its form. However, this tractability does not come at the cost of intuitive reasoning; after all, the assumed form implies that the positive health impact of public spending is more pronounced in conducive natural environments. ${ }^{8}$

Agents maximize their ex ante (i.e., expected) lifetime utility function

$$
V^{t}=\ln c_{t}+\beta_{t} \ln d_{t+1},
$$

where $c_{t}$ and $d_{t+1}$ denote the levels of consumption during youth and old age, respectively.

There is a single, perishable commodity. It is produced by perfectly competitive firms, who combine physical capital $K_{t}$ (which they rent from financial intermediaries at a price of $R_{t}$ per unit) and labor $L_{t}$ to produce output $Y_{t}$. The production function is

$$
Y_{t}=\mathrm{A} K_{t}^{\gamma}\left(L_{t} \bar{K}_{t}\right)^{1-\gamma}, 0<\gamma<1,
$$

where A $>0$ and $\bar{K}_{t}$, which denotes the economy's average amount of capital, captures an economywide learning-by-doing externality, as in Romer (1986).

One unfortunate by-product from firms' activities is pollution. We assume that one unit of output generates $\tilde{p}_{t}>0$ units of pollutant emissions; therefore, total pollution is

$$
P_{t}=\widetilde{p}_{t} Y_{t}
$$

The amount of pollution can be mitigated by government-funded activities that are designed and implemented to reduce the extent of environmental damage. For the purposes of our analysis, we refer to them as pollution abatement activities. Following the literature, we distinguish between two types of abatement technologies. The first type is process-integrated technology, which alters the production process in a more environmentally friendly way and hence reduces the emission-to-output ratio (or the emission intensity), $\widetilde{p}_{t}$. In other words, this type of abatement technology reduces the amount of contaminants per unit of output, before they form. It can be represented as $\tilde{p}_{t}=\tilde{p}\left(a_{t}\right)$, where $a_{t}$ denotes abatement activities that are of the process-integrated type and $\widetilde{p}^{\prime}<0$. An example of the functional form $\tilde{p}$ that we use in the following is

$$
\widetilde{p}_{t}=\frac{p}{1+a_{t}}, p>0 .^{9}
$$

For further details regarding this type of abatement technology see Requate (2005), Clemens and Pittel (2011), Endres and Friehe (2013), to name but a few.

The second type of abatement activities, which we analyze in Section 5, use end-of-pipe technology. This technology does not modify the production process and hence does not change the emission-to-output ratio, $\tilde{p}_{t}$. Instead, it is used after the production process to remove already formed contaminants. End-of-pipe 
abatement technology is analyzed in, among others, Diamantoudi and Sartzetakis (2006), Economides and Philippopoulos (2008), and Marianni et al. (2010).

Restricting the analysis for now only to process-integrated abatement, we write

$$
P_{t}=\frac{p Y_{t}}{1+a_{t}} .
$$

The quality of the natural environment, $e_{t} \geq 0$, depends on the extent of environmental degradation. We capture this idea through

$$
e_{t}= \begin{cases}E-P_{t} & \text { if } P_{t}<E \\ 0 & \text { otherwise }\end{cases}
$$

where $E>0$ allows us to consider an environmental tipping point. This is a situation that occurs when the environmental impact of human activities exceeds a critical threshold, after which the conditions for meaningful existence of the Earth's species (including humans) are severely undermined. In our model, this occurs whenever $P_{t} \geq E$. The importance of such tipping points for various environmental indicators is now well established among scientists [see, for example, Barnosky et al. (2012)] and it has been used in existing analyses examining the interactions between economic growth and the environment [e.g., Acemoglu et al. (2012)].

As is evident in (8), we abstract from the dynamics of environmental quality by assuming that $e_{t}$ is a flow and not a stock variable. This choice has been dictated by the need for analytical tractability. As will become clear later, even in its current form the model is very complicated and any analytical solutions that allow the reader to understand the intuition and the mechanisms involved are possible only when environmental quality is a flow variable. Nevertheless, in order to show that our results survive under more general settings, in Section 4 we solve the model for the case where environmental quality is a stock that evolves according to $e_{t}=\eta e_{t-1}+(1-\eta) E-P_{t}(0<\eta<1)$, a specification that follows the seminal work by John and Pecchenino (1994). As we shall see, our main results and their implications survive even in this more general setting. ${ }^{10}$

We complete our description of the economy's structure with a discussion of the process under which the government finances its activities. We adopt the widely used assumption that the government imposes a flat tax rate $\tau \in(0,1)$ on firms' revenue. Assuming that the government abides by a balanced budget rule in each period, our previous assumptions imply that $g_{t}+a_{t}=\tau Y_{t}$. If we denote the fixed fraction of revenue devoted to abatement by $v \in[0,1)$, it is straightforward to establish that

$$
g_{t}=(1-v) \tau Y_{t}
$$

and

$$
a_{t}=v \tau Y_{t}
$$

give the levels of public health spending and abatement activities in relation to the economy's total output. 


\section{EQUILIBRIUM}

\subsection{Temporary Equilibrium}

We begin our analysis with a description of the economy's temporary equilibrium.

DEFINITION 1. The temporary equilibrium of the economy is a set of quantities $\left\{c_{t}, d_{t}, d_{t+1}, s_{t}, L_{t}, Y_{t}, \beta_{t}, h_{t}, e_{t}, P_{t}, a_{t}, g_{t}, K_{t}, K_{t+1}\right\}$ and prices $\left\{w_{t}, R_{t}, R_{t+1}, r_{t+1}\right\}$ such that:

(i) Given $w_{t}, r_{t+1}$, and $\beta_{t}$, the quantities $c_{t}, d_{t+1}$, and $s_{t}$ solve the optimization problem of an agent born at time $t$.

(ii) Given $w_{t}$ and $R_{t}$, all firms choose quantities for $L_{t}$ and $K_{t}$ to maximize profits.

(iii) All markets clear.

(iv) The government budget is balanced.

The objective of a young agent is to choose her intertemporal consumption profile to maximize $V^{t}$ subject to $c_{t}=w_{t}-s_{t}$ and $d_{t+1}=r_{t+1} s_{t}$. Alternatively, given (3), the problem can be modified to $\max _{0 \leq s_{t} \leq 1}\left\{\ln \left(w_{t}-s_{t}\right)+\beta_{t} \ln \left(r_{t+1} s_{t}\right)\right\}$. The solution to this problem is

$$
s_{t}=\frac{\beta_{t}}{1+\beta_{t}} w_{t} .
$$

Naturally, the prospect of premature death modifies an agent's saving behavior. An increase in longevity raises the marginal utility of an agent's consumption when old; to restore the equilibrium, the marginal utility derived from her firstperiod consumption must increase as well. She can achieve this by choosing to save more and consume less while she is young.

Profit maximization implies that

$$
w_{t}=(1-\tau)(1-\gamma) \mathrm{A} K_{t}^{\gamma} L_{t}^{-\gamma} \bar{K}_{t}^{1-\gamma}
$$

and

$$
R_{t}=(1-\tau) \gamma \mathrm{A} K_{t}^{\gamma-1} L_{t}^{1-\gamma} \bar{K}_{t}^{1-\gamma} .
$$

At equilibrium, $L_{t}=1$ and $k_{t}=K_{t}=\bar{K}_{t}$, where $k_{t}=K_{t} / L_{t}$ is capital per worker. Consequently, we can write (12) and (13) as

$$
w_{t}=(1-\tau)(1-\gamma) \mathrm{A} k_{t}
$$

and

$$
R_{t}=(1-\tau) \gamma \mathrm{A} \equiv \hat{R}
$$

There are two conditions that describe the financial market equilibrium. We assume that perfectly competitive financial intermediaries undertake the task of channeling capital from depositors to firms. Specifically, they transform savings deposits into capital by accessing a technology that transforms time- $t$ output into time- $(t+1)$ capital on a one-to-one basis. They subsequently supply this capital 
to firms that manufacture the economy's single commodity. Hence, $K_{t+1}=L_{t} s_{t}$, or in intensive form,

$$
k_{t+1}=s_{t}
$$

To resolve the issue of saving under an uncertain lifetime, we assume, following Chakraborty (2004), that financial intermediaries represent mutual funds that offer contingent annuities. Specifically, when accepting deposits, intermediaries promise to offer retirement income (in our case, $r_{t+1} s_{t}$ ) provided that the depositor survives to old age. Otherwise, the income of those who die is shared equally among surviving members of the mutual fund. Considering this assumption, and the fact that financial intermediaries operate under perfect competition, we have

$$
\beta_{t} r_{t+1}=R_{t+1}=\hat{R}
$$

which translates into the equilibrium condition requiring costs to be equal to revenue.

Next, we substitute $L_{t}=1$ in (4) to obtain output per worker $y_{t}=Y_{t} / L_{t}$ :

$$
y_{t}=\mathrm{A} k_{t} .
$$

If we combine the expression in (18) with (1), (2), (5), (6), (7), (8), (9), and (10), and substitute together with (11) and (14) in (16), we can eventually derive

$$
k_{t+1}=(1-\tau)(1-\gamma) \mathrm{A} \frac{\mathrm{B}\left(\left[(1-v) \tau \mathrm{A} k_{t}\right]^{\varphi}\left(E-\frac{p \mathrm{~A} k_{t}}{1+v \tau \mathrm{A} k_{t}}\right)^{\chi}\right)}{1+\mathrm{B}\left(\left[(1-v) \tau \mathrm{A} k_{t}\right]^{\varphi}\left(E-\frac{p \mathrm{~A} k_{t}}{1+v \tau \mathrm{A} k_{t}}\right)^{\chi}\right)} k_{t}=z\left(k_{t}\right),
$$

which is a first-order difference equation in capital per worker. The analysis of this equation will facilitate us in understanding the dynamics and the longrun equilibrium of the economy. This is the issue to which we now turn our attention. Before we proceed, we should note that all the proofs are presented in the Appendix.

\subsection{Dynamic Equilibrium}

The economy's dynamic equilibrium is formally described through

DEFINITION 2. Given $k_{0} \geq 0$, the dynamic equilibrium is a sequence of temporary equilibria that satisfy $k_{t+1}=z\left(k_{t}\right)$ for every $t$.

We can facilitate our subsequent analysis by defining a new variable, $\theta_{t+1}$, which denotes the growth rate of physical capital per worker, $k$. That is,

$$
\theta_{t+1}=\frac{k_{t+1}}{k_{t}}-1 .
$$

Furthermore, our subsequent results will be further clarified with the use of 


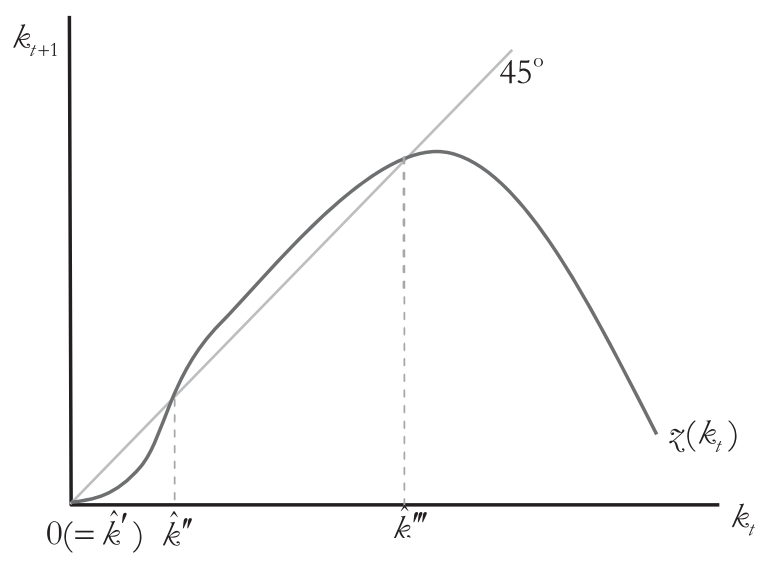

FigURE 1. $v=0$ and $0<z^{\prime}\left(\hat{k}^{\prime \prime \prime}\right)<1$.

DEFINITION 3. Consider $k_{0} \geq 0$. An equilibrium orbit $\left\{k_{t}\right\}$ is a no growth equilibrium if there exists $M>0$ such that $k_{t}<M \forall t$. If $\lim _{t \rightarrow \infty} k_{t}=\hat{k}$ then we call $\hat{k}$ a no growth steady-state equilibrium. If, in addition, $\hat{k}=0$, then the equilibrium is a poverty trap. If there does not exist such an $M$, then the equilibrium orbit is called a long-run growth equilibrium and satisfies $\lim _{t \rightarrow \infty} \frac{k_{t+1}}{k_{t}}=\lim _{t \rightarrow \infty}\left(1+\theta_{t+1}\right)>1$.

Our purpose is to examine two scenarios that differ with respect to the government's provision of pollution abatement services. As we shall see, the public sector's stance on environmental protection has significant repercussions for both the economy's dynamics and its long-term prospects. Furthermore, the subsequent analysis will be utilizing

Assumption 1.

$$
(1-\tau)(1-\gamma) \mathrm{A} \frac{\mathrm{B}(\Omega)}{1+\mathrm{B}(\Omega)}>1, \quad \text { where } \Omega=\left(\frac{\varphi \tau}{p}\right)^{\varphi} \chi^{\chi}\left(\frac{E}{\varphi+\chi}\right)^{\varphi+\chi} .
$$

Assumption 1 is essential for the existence of a meaningful long-run equilibrium and is very common in overlapping-generations economies. As we shall see later, the slope of the phase line at the origin is below unity-an outcome that raises the possibility that the only steady-state equilibrium entails the corner solution of a zero capital stock. Assumption 1 eliminates this possibility and ensures the existence of an interior equilibrium (see Figure 1) by requiring that the structural parameters conducive to the economy's capital formation (such as the productivity parameter $\mathrm{A}$; the parameters of the health function $\mathrm{B}(\cdot)$; or the environmental parameter $E$ ) be sufficiently high to guarantee a positive rate of capital accumulation for at least some range on the capital stock's domain. In economic terms, Assumption 1 requires that, over some range of the capital stock, the savings of the young suffice to buy the existing capital stock. 


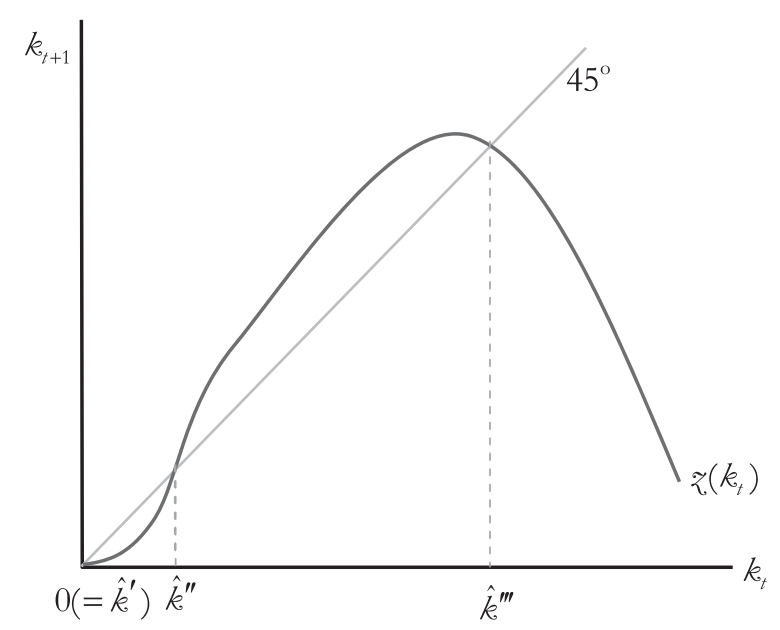

FigURE 2. $v=0$ and $-1<z^{\prime}\left(\hat{k}^{\prime \prime \prime}\right)<0$.

\subsection{Dynamic Equilibrium without Abatement}

We begin our analysis with the case where the fraction of revenue devoted to abatement $v=0$, i.e., the government does not actively engage in policies of environmental preservation. Given (19), we have

$$
z\left(k_{t}\right)=(1-\tau)(1-\gamma) \mathrm{A} \frac{\mathrm{B}\left(\left(\tau \mathrm{A} k_{t}\right)^{\varphi}\left(E-p \mathrm{~A} k_{t}\right)^{\chi}\right)}{1+\mathrm{B}\left(\left(\tau \mathrm{A} k_{t}\right)^{\varphi}\left(E-p \mathrm{~A} k_{t}\right)^{\chi}\right)} k_{t} .
$$

First, we are interested in obtaining the model's steady-state equilibria. These are fixed points of the map $z(\cdot)$, i.e., values $\hat{k}$ of capital per worker that satisfy $\hat{k}=z(\hat{k})$. A formal analysis of (21) allows us to derive

LEMMA 1. There exist three steady-state equilibria, $\hat{k}^{\prime}, \hat{k}^{\prime \prime}$, and $\hat{k}^{\prime \prime \prime}$, where $\hat{k}^{\prime}=0$ and $\hat{k}^{\prime \prime \prime}>\hat{k}^{\prime \prime}>0$. The steady state $\hat{k}^{\prime}$ is locally asymptotically stable, $\hat{k}^{\prime \prime}$ is unstable, and $\hat{k}^{\prime \prime \prime}$ may be either locally asymptotically stable or unstable.

The result from Lemma 1 facilitates us in tracing the economy's dynamic behavior and transitional dynamics. We can formally present these ideas in the form of

PROPOSITION 1. Assume $k_{0}>0$. Then

(i) If $k_{0}<\hat{k}^{\prime \prime}$, the economy will converge to the poverty trap $\hat{k}^{\prime}=0$.

(ii) If $k_{0}>\hat{k}^{\prime \prime}$, the economy will converge to a no growth equilibrium. Particularly, if $\hat{k}^{\prime \prime \prime}$ is locally asymptotically stable, then it will also be the stationary equilibrium for the stock of capital per worker-otherwise, the economy will asymptotically converge to an equilibrium where capital per worker displays permanent cycles around $\hat{k}^{\prime \prime \prime}$. 


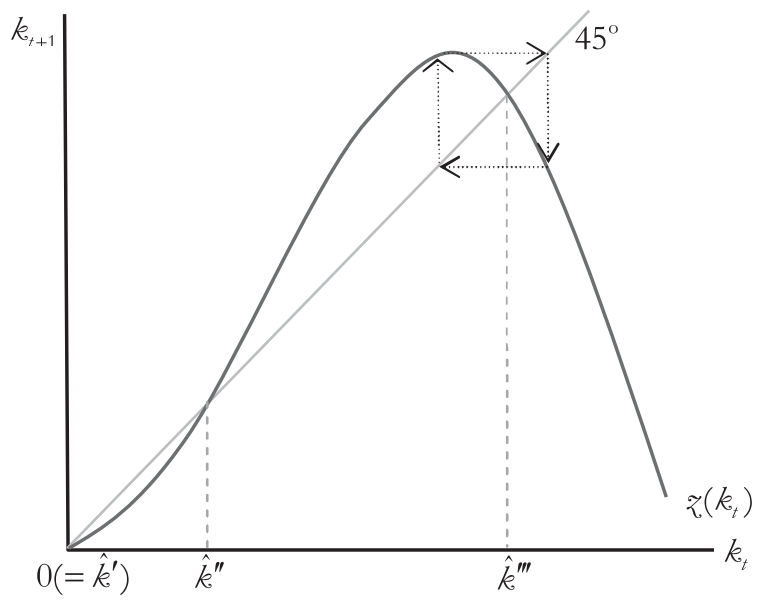

FIGURE 3. $v=0$ and $z^{\prime}\left(\hat{k}^{\prime \prime \prime}\right)<-1$ : an example with a period- 2 cycle.

The different possible scenarios are depicted in Figures 1-3. In all three cases, we see that the point $\hat{k}^{\prime \prime}$ acts as a natural threshold, which allows history (approximated by the initial capital stock) to determine the long-term prospects of the economy. The model's ability to generate multiple steady-state equilibria rests on the beneficial effect of publicly provided health services on saving behavior - an effect that rests on the idea that health services promote longevity. Specifically, for some levels of $k_{t}$, capital accumulation and saving complement each other. Thus, for relatively low levels of initial capital endowment, saving is not sufficient enough to guarantee a positive rate of capital accumulation: capital per worker declines constantly until it rests on an equilibrium that is, essentially, a poverty trap. If, however, the initial endowment is sufficient enough, the economy can escape the poverty trap because saving allows growth at positive (albeit declining) rates during the early stages of transition.

So far, the results and their intuition are similar to those discussed in Chakraborty (2004). Nevertheless, our model is able to generate richer implications for the dynamics of an economy whose history allows it to move to the right side of the natural threshold $\hat{k}^{\prime \prime}$. The reason for such implications is economic activity's contribution to environmental degradation and the corresponding repercussions for health status and longevity. Particularly, for sufficiently high values of $k_{t}$, the negative effect of pollution on life expectancy and saving dominates the positive effect of publicly provided goods and services on health. Hence, the dynamics of capital accumulation are nonmonotonic and $\hat{k}^{\prime \prime \prime}$ may actually lie on the downwardsloping part of $z\left(k_{t}\right)$ (see Figures 2 and 3). Furthermore, as Figure 3 illustrates, when the slope of the graph in the steady state $\hat{k}^{\prime \prime \prime}$ is steep enough, the economy may converge to an equilibrium in which capital per worker oscillates permanently around $\hat{k}^{\prime \prime \prime}$, i.e., an equilibrium with a permanent, endogenously determined cycle. In terms of intuition, a relatively high level of capital per worker implies relatively 
high pollution. The health status is affected negatively and, consequently, saving is reduced. Capital accumulation is mitigated, but this also implies that the extent of environmental degradation is mitigated as well. Next period's health status improves and so does saving, which promotes capital accumulation. This sequence of events may ultimately become self-repeating, thus generating an equilibrium with persistent cycles. ${ }^{11}$

Concerning the dynamic behavior of environmental quality, it should be obvious that this will be dictated by the dynamics of the capital stock. More specifically, if the economy converges to a poverty trap, then environmental quality approaches its maximum level $E$ given that economic activity is the ultimate cause of environmental deterioration; nevertheless, the severe limitation of resources for public health means that agents cannot benefit from the improved environmental conditions and, hence, they live essentially for one period. If, on the other hand, the capital stock converges to a stationary or a periodic equilibrium, then so does environmental quality (the dynamics of environmental quality are analyzed formally in the Appendix; see Section A.5).

These results, as well as the intuition behind them, merit some discussion in relation to their empirical relevance. As we can see, the equilibrium behavior of all variables, including environmental quality and life expectancy/mortality, can be cyclical under some circumstances. With respect to the former, there is evidence that indicators of environmental quality display such cyclical movements [e.g., Mayer (1999)]. With respect to the latter, the analyses of Chay and Greenstone (2003) and Rolden et al. (2014) make an explicit connection between pollution and procyclical mortality rates. In any case, the subsequent section of our analysis will show that in the presence of environmental policy, the economy's dynamics and the repercussions for life expectancy become drastically different. Thus, an additional implication will be the identification of the possible importance of environmental policy in preserving the positive, on the average, link between longevity and per capita GDP that we observe in cross-sectional data.

\subsection{Dynamic Equilibrium with Active Pollution Abatement}

Next, we analyze the scenario where $0<v<1$, i.e., the government pursues a policy of environmental preservation. As a result, the dynamics of capital accumulation are represented by the difference equation we originally obtained in (19). Once more, we begin our analysis with the derivation of the model's steady-state equilibrium.

LEMMA 2. Suppose that $\tau>p / v E$ holds. Then there exist two steady-state equilibria, $\hat{k}_{1}$ and $\hat{k}_{2}$, such that $\hat{k}_{2}>\hat{k}_{1}=0$. The steady state $\hat{k}_{1}$ is locally asymptotically stable, whereas the steady state $\hat{k}_{2}$ is unstable.

The condition $\tau>p / v E$ imposes a lower bound on the share of government expenditure that is allocated to abatement. Equivalently, it imposes an upper bound on the maximum emission rate $p$, so that, even at very high levels of output, the 


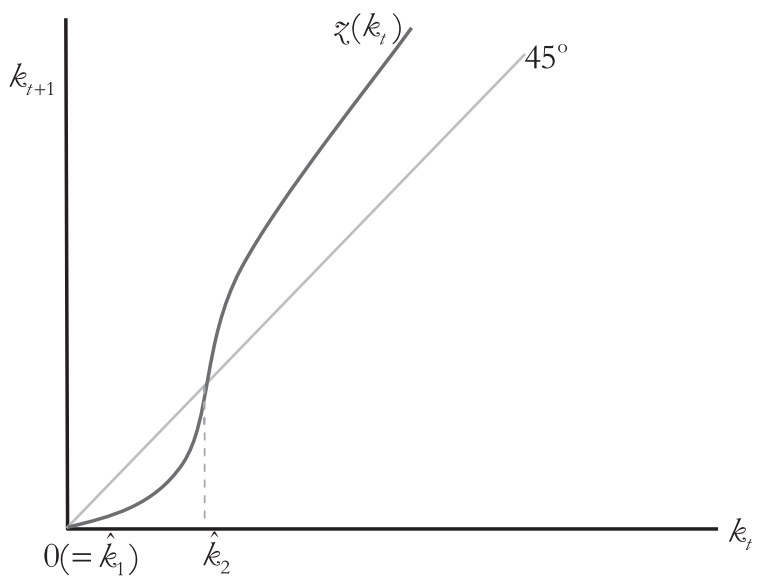

FIGURE 4. $0<v<1$.

effect of degradation due to pollution does not exceed the natural capacity of the environment (i.e., $E$ ). If this condition does not hold, the dynamic equilibrium of the economy resembles the one derived for $v=0$. Using Lemma 2, we can identify the economy's dynamic behavior. We do this through

PROPOSITION 2. Assume $k_{0}>0$. Then

(i) If $k_{0}<\hat{k}_{2}$, the economy will converge to the poverty trap $\hat{k}_{1}=0$.

(ii) If $k_{0}>\hat{k}_{2}$, then the economy will converge to a long-run growth equilibrium in which both capital and output per worker grow at the rate $\hat{\theta}=(1-\tau)(1-\gamma) \mathrm{A} \frac{\lambda}{1+\lambda}-1>0 .{ }^{12}$

The dynamics of the economy with pollution abatement are illustrated in Figure 4 . The steady state $\hat{k}_{2}$ emerges as an endogenous threshold that determines long-term prospects according to the initial capital stock. Once more, an economy that is initially endowed with resources below this threshold will degenerate toward the poverty trap, where capital and output are very low-so low, in fact, that the reduced pollution cannot be translated into improvements in the health characteristics of the population. Naturally, the intuition behind this result is identical to that provided in the case without pollution abatement.

Of particular interest is the situation that occurs when the initial capital stock is above $\hat{k}_{2}$. In contrast to the $v=0$ case, in which capital converges to an equilibrium without growth (i.e., either a positive level or a limit cycle), in this case the economy is able to sustain a positive growth rate in the long run. The reason is that abatement limits the extent to which economic activity causes environmental damage. Thus, it protects the population's health against the damage from environmental degradation; therefore, agents' saving behavior is not impeded as the economy grows. Combined with the effect of the learning-by-doing externality in production, a policy of environmental preservation allows the social 
marginal return of capital to be high enough to guarantee a positive rate of capital accumulation that eventually allows the economy to achieve balanced growth as an equilibrium outcome. Moreover, as the economy grows without bound, environmental quality approaches from above the constant level $E-(p / v \tau)$; for this to be positive it must be the case that $\tau>p / v E$, which we assumed in Lemma $2 .^{13}$

\subsection{Some Important Implications}

In the preceding sections, we have examined the transitional dynamics and the long-term equilibrium of an economy under two opposite scenarios concerning the government's engagement in policies that are designed to mitigate pollution and promote environmental quality. Apart from the common theme of multiple steady states and the existence of poverty traps, the predictions from the two scenarios concerning the long-term prospects of economies that escape such poverty traps are strikingly different. The purpose of this section is to compare and contrast these predictions in order to derive important implications that arise as a result of the government's stance on activities of pollution abatement.

We begin with the implications concerning economic growth. Equation (4) implies that labor's contribution to aggregate production is augmented by a productivity variable that is driven by the presence of an economywide learning-bydoing externality, as in Romer (1986). It is well known that, in standard dynamic general equilibrium models with production, such externalities allow the emergence of equilibria with ongoing output growth. In our framework, however, we have established that the learning-by-doing mechanism is not by itself sufficient to guarantee growth in the long run. Indeed, such an equilibrium exists only when the government commits sufficient resources to activities that abate pollution. Therefore, one significant implication from our analysis is the following:

COROLLARY 1. For an economy that avoids the poverty trap, pollution abatement is a complementary engine of long-run economic growth.

This idea comes in stark contrast to previously held views concerning the macroeconomic repercussions of pollution. In her influential paper, Stokey (1998) argued that the prospects for long-run growth may be hampered as a result of society's need to implement policies that support the quality of the natural environment - policies that are costly and therefore reduce the marginal product of capital to the extent that capital accumulation cannot be permanently sustained. By taking account of the well-documented effects of environmental quality on the overall health characteristics of the population, and their consequences for saving behavior, our model has reached a different conclusion: policies that preserve some degree of environmental quality are actually essential for the existence of an equilibrium with ongoing output growth. Furthermore, notice that for environmental policy to achieve this outcome, we do not require an equilibrium in which 
pollution declines constantly over time [see, for example, Smulders and Gradus (1996)]. In fact, pollution abatement supports long-run growth even though it is only capable of reducing the rate of environmental degradation, rather than eliminating it altogether.

Another important implication of our analysis is related to the existence of limit cycles. As we have seen, when pollution abatement is absent, it is possible for capital per worker to oscillate permanently around its positive steady state. Of course, such persistent fluctuations are different in nature from cycles whose impulse sources may be exogenous demand and/or supply disturbances. In our model, both the impulse source and the propagation mechanism of cycles rest on the presence of nonmonotonicity in the dynamics of capital accumulation. Naturally, policies that could eradicate such fluctuations are policies that would address the source of nonmonotonicities rather than countercyclical rules designed to mitigate temporary fluctuations around a given trend. With this in mind, a straightforward comparison between our two different scenarios allows us to infer.

COROLLARY 2. For an economy that avoids the poverty trap, pollution abatement is a source of stabilization, in the sense that it eliminates the possibility of permanent cycles.

Given that environmental policy has an indirect positive effect on health, and consequently life expectancy, our model derives implications that differ from those of Bhattacharya and Qiao (2007). In their model, the positive complementarities between private and public health spending imply that there is a trade-off between saving and private health expenditure. This trade-off generates nonmonotonic capital dynamics, rendering health-enhancing public policy a source of endogenous fluctuations. In our model, a policy that facilitates health improvements (albeit indirectly through pollution abatement) actually eliminates such fluctuations.

At this point it is important to discuss a conceptual issue that is related to Corollaries 1 and 2. Given the combined modeling of life expectancy, environmental quality, and pollution abatement, one may wonder why the environmental policy of abatement and its link to pollution are critical for the results. After all, pollution abatement affects saving behavior and capital accumulation in the same manner as direct expenditure on health $\left(g_{t}\right)$ : both of them improve health and life expectancy. The reason that environmental policy is critical, and its effects quite different from the direct effects of public health spending, is the following. In the absence of pollution abatement, an increase in capital stock, production, and thus income has two conflicting effects. On one hand, it raises tax revenue and hence spending on health services, and, on the other, it raises pollution and worsens environmental degradation. The first effect improves agents' health status and hence increases their saving rate, whereas the second worsens their health status and decreases the saving rate. It is exactly this interplay between environmental degradation and health services that environmental policy breaks. It mitigates the source of nonmonotonicities, i.e., the rate of environmental degradation that leads to endogenous cycles and does not allow the economy to grow in the long run. 
This becomes obvious from the fact that when $a_{t}=0$, the no-growth equilibrium (and, possibly, cycles) emerges even in the presence of $g_{t}$, i.e., the part of public spending directly devoted to health.

Another way to see the point made in the preceding paragraph is to consider a case where the link between $a_{t}$ and environmental quality is removed. For example, consider the case where the health function is given by $h_{t}=g_{t}^{\varphi} e_{t}^{\chi} a_{t}^{\zeta}$, $\zeta>0, P_{t}=p Y_{t}$, and hence $e_{t}=E-p Y_{t}$. Life expectancy then equals $1+B\left(h_{t}\right)=$ $1+B\left((1-v)^{\varphi} v^{\zeta}(\tau \mathrm{A})^{\varphi+\zeta} k_{t}^{\varphi+\zeta}\left(E-p \mathrm{~A} k_{t}\right)^{\chi}\right)$. Substituting this into the transition equation, one can easily establish that even when $v>0$, the model would behave qualitatively identically to the scenario we presented in Section 3.3 (summarized in Proposition 1). Nevertheless, this would be a scenario in which there was conceptually nothing to specify $a_{t}$ as pollution abatement. Instead, $a_{t}$ behaves identically to $g_{t}$, as just another item of spending that improves health directlyin fact, one can consider $g_{t}^{\varphi} a_{t}^{\zeta}$ as a composite term manifesting the direct effect of public spending on health. In contrast, although the effect of $a_{t}$ is ultimately a benefit in terms of health and life expectancy, the transmission of this effect in our original formulation entails a direct reduction of emissions per unit of output. It is for this reason that $a_{t}$ can be conceptually associated with pollution abatement in the first place, whereas our setup and implications differ from a typical $\mathrm{A} K$ growth model with public health expenditure.

\section{ENVIRONMENTAL QUALITY AS A STOCK VARIABLE}

Next, to test the robustness of our results, we consider environmental quality as a stock, instead of a flow, variable. We should note that using environmental quality as the variable of concern, and assuming that its dynamic behavior is affected by the flow of emissions, is not an alien assumption. On the contrary, a similar approach has been used by seminal analyses in the context of either OLG economies [e.g., John and Pecchenino (1994); Mariani et al. (2010)] or representative-agent ones [e.g., Bovenberg and Smulders (1995); Acemoglu et al. (2012)]. To that end, we replace equation (8) with the following equation:

$$
e_{t}= \begin{cases}(1-\eta) E+\eta e_{t-1}-P_{t} & \text { if } P_{t}<(1-\eta) E+\eta e_{t-1} \\ 0 & \text { otherwise }\end{cases}
$$

where $P_{t}$ is given in equation (7) (an alternative specification, mentioned in note 10 , is presented in the working paper version). Equation (22) follows John and Pechennino (1994). ${ }^{14}$ Accordingly, environmental quality is now a convex combination of the maximum long-run level of environmental quality $E$ and the environmental quality of the last period. Notice that this formulation can also encompass the case analyzed in Sections 2 and 3; specifically, if $\eta=0$, then equation (22) is reduced to $(8)$. 
Using $m_{t+1}=e_{t}$ and following the same steps as before, we can reduce the model to the following planar system of difference equations:

$$
\begin{gathered}
k_{t+1}=(1-\tau)(1-\gamma) \mathrm{A} \frac{\mathrm{B}\left(\left[(1-v) \tau \mathrm{A} k_{t}\right]^{\varphi}\left[(1-\eta) E+\eta m_{t}-\frac{p \mathrm{~A} k_{t}}{1+v \tau k_{t}}\right]^{\chi}\right)}{1+\mathrm{B}\left(\left[(1-v) \tau \mathrm{A} k_{t}\right]^{\varphi}\left[(1-\eta) E+\eta m_{t}-\frac{p \mathrm{~A} k_{t}}{1+v \tau \mathrm{A} k_{t}}\right]_{(\mathbf{2 3})}^{\chi}\right)} k_{t} \\
m_{t+1}=(1-\eta) E+\eta m_{t}-\frac{p \mathrm{~A} k_{t}}{1+v \tau \mathrm{A} k_{t}} .
\end{gathered}
$$

Unlike the one-dimensional system analyzed in Section 3, the two-dimensional system of difference equations in this case is quite complex. To simplify the analysis, we adopt the functional form $B\left(h_{t}\right)=\lambda h_{t} /\left(1+h_{t}\right)(0<\lambda<1)$ that was suggested by Chakraborty (2004). This is a functional form that satisfies all the properties listed after (1). Moreover, we let $\varphi=\chi=1$, so that (23) becomes

$$
k_{t+1}=\frac{(1-\tau)(1-\gamma) \lambda(1-v) \tau \mathrm{A}^{2} k_{t}^{2}\left[(1-\eta) E+\eta m_{t}-\frac{p \mathrm{~A} k_{t}}{1+v \tau \mathrm{A} k_{t}}\right]}{1+(1+\lambda)(1-v) \tau \mathrm{A} k_{t}\left[(1-\eta) E+\eta m_{t}-\frac{p \mathrm{~A} k_{t}}{1+v \tau \mathrm{A} k_{t}}\right]} .
$$

When (24) and (25) are combined, the steady-state loci $k_{t+1}=k_{t}=k$ and $m_{t+1}=m_{t}=m$ are given by

$$
\begin{aligned}
m & =\frac{1}{\eta}\left\{\frac{1}{[(1-\tau)(1-\gamma) \mathrm{A} \lambda-(1+\lambda)] \mathrm{A} \tau(1-v) k}\right. \\
& \left.-\left((1-\eta) E-\frac{p \mathrm{~A} k}{1+v \tau \mathrm{A} k}\right)\right\}
\end{aligned}
$$

and

$$
m=E-\frac{1}{1-\eta} \frac{p \mathrm{~A} k}{1+v \tau \mathrm{A} k} .
$$

PROPOSITION 3.

(i) If $v=0$, then for sufficiently high value of $p$ there is no positive steady state, whereas for sufficiently low value of $p$ there are two positive steady states.

(ii) If $v>p /(\tau(1-\eta) E)>0$, then there is only one nondegenerate positive steady state.

Proposition 3 is illustrated in Figures 5 and 6. If there is no abatement and the maximum emission rate $p$ is sufficiently high, then there is no positive steady state (the two loci $\Delta m_{t}=0$ and $\Delta k_{t}=0$ in Figure 5 do not intersect). In fact, as a straightforward analysis of the phase diagram shows, the economy converges to the steady state $(k, m)=(0, E)$. This case then represents that of a poverty trap (recall that a similar result was obtained in Section 3). If, on the other hand, $p$ is sufficiently low, then there will be two steady states. For example, if we use the values $\tau=0.4, \gamma=0.4, p=0.3, \mathrm{~A}=25, E=10$, and $\eta=0.8$, there are two steady-state equilibria. If we specify $\lambda=0.4$, then the two equilibria are 


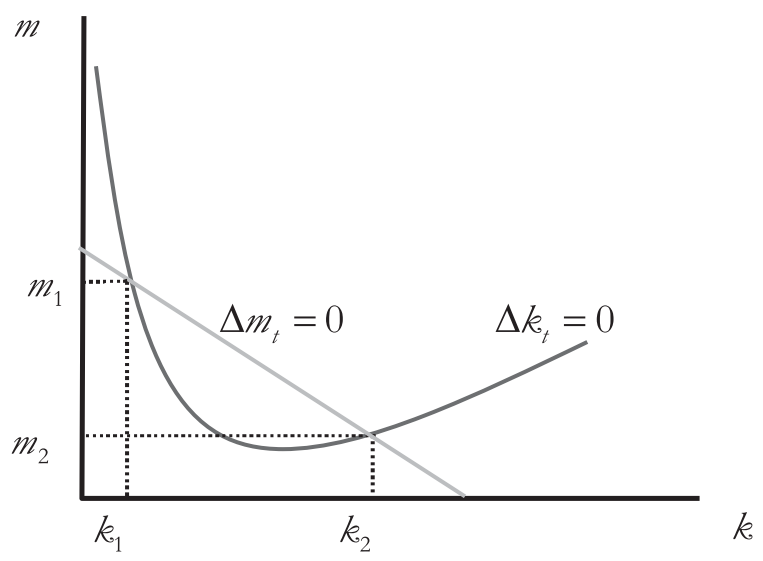

FIGURE 5. Multiple equilibria with environmental quality as in (22) and $v=0$.

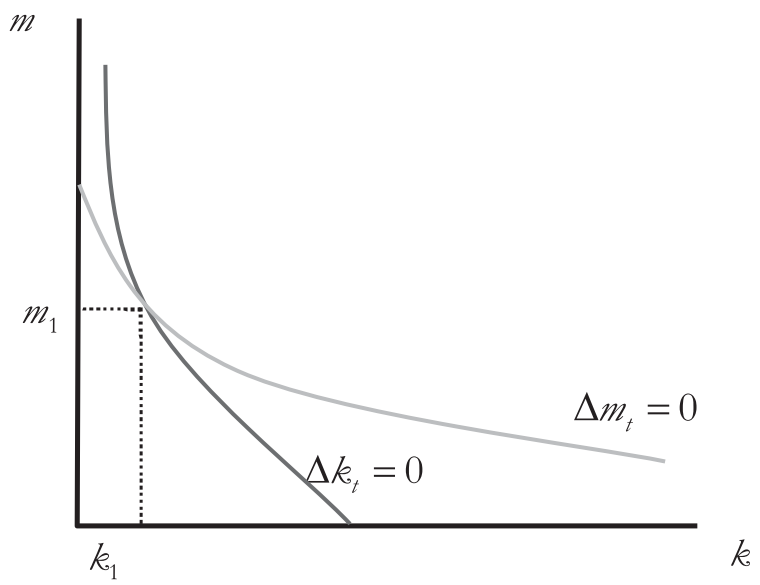

FIGURE 6. Pollution abatement $(v>0)$ with environmental quality as in (22).

$\left(k_{1}, m_{1}\right)=(0.005,9.827)$ and $\left(k_{2}, m_{2}\right)=(0.262,0.173)$. Moreover, when $\lambda=$ 0.4 , at both equilibria the eigenvalues are real; one of them has modulus greater and the other less than one. Thus, both equilibria are saddlepath stable. Nevertheless, the stability properties of the equilibria change with $\lambda$. In fact, as shown in the Appendix (see Section A.8), an attracting two-period cycle may emerge. For example, if, again, $\lambda=0.4$, then the two-period cycle includes the points $(0.202$, $0.075)$ and $(0.315,0.547)$. Hence, given that $m_{t+1}=e_{t}$, the economy converges to an equilibrium where it oscillates between $(k, e)=(0.202,0.547)$ and $(k, e)=$ $(0.315,0.075)$. Just as in Section 3 , where $e$ was a flow variable, low (high) capital stock implies low (high) pollution and high (low) environmental quality.

Consider, next, the case where there is pollution abatement, that is, $v>0$. If, as in Lemma 2, the percentage of tax revenue that the government allocates to 
abatement $(v)$ is high enough $\{v>p /[\tau(1-\eta) E]\}$, then there will be a unique steady-state equilibrium (see Figure 6). For the values specified earlier, $v=0.5$, and $\lambda=0.4$, the unique steady-state equilibrium is $\left(k_{1}, m_{1}\right)=(0.009,9.663)$ and it is saddlepath stable. In this case, no cycle emerges. An economy whose initial capital stock is greater than $k_{1}$, and not on the saddlepath, will be able to grow unboundedly.

We conclude that extending the analysis to consider the stock of the natural environment (a form of natural capital) has not affected the qualitative implications of our original setup. This outcome is not surprising. In both scenarios regarding the setup for $e_{t}$ (flow and stock), the model's mechanisms, as well as the manner in which pollution abatement impinges on them, are the same. Without pollution abatement, the impact of capital accumulation on total emissions has a strong negative effect on the evolution of $e_{t}$ (the dynamics of environmental quality). Given the two-way causal nature behind the joint dynamics of $k_{t}$ and $e_{t}$, the deteriorating environmental conditions will impinge on life expectancy and saving, inhibiting capital accumulation and the flow of emissions, and thus improving the evolution of environmental quality and perpetuating the cyclical dynamics. Pollution abatement can mitigate the rate of environmental deterioration, hence reducing the magnitude of the forces that inhibit the prospects of long-run growth and lead to cycles. The lagged effect associated with treating $e_{t}$ as a stock variable does not change the model's mechanisms and intuition when it comes to the issue of pure economic dynamics - the issue that is the main concern of our framework.

\section{ALTERNATIVE SPECIFICATIONS}

As further tests of robustness, in this section we examine two alternative specifications. ${ }^{15}$ First, we replace process-integrated technology with end-of-pipe technology. For this, we set $a_{t}=0$ in equations (6) and (7), so that $P_{t}=p Y_{t}$. Recall that the end-of-pipe abatement technology does not modify the production process and hence does not change the emission-to-output ratio. Instead, it can clean already formed contaminants. Hence, we have to distinguish now between pollution and environmental degradation (net pollution). The latter is denoted by $D_{t}$, and it is given by

$$
D_{t}=P_{t}-f\left(P_{t}, a_{t}\right)=D\left(P_{t}, a_{t}\right)
$$

where $D_{P}>0$ and $D_{a}<0$, so that environmental degradation increases with the flow of pollution $(P)$ and decreases with abatement activities $(a)$. To be able to derive analytical solutions, we assume the functional form $f\left(P_{t}, a_{t}\right)=P_{t}^{-\sigma} a_{t}^{\varepsilon}$, where $\sigma \geq 0$ and $\varepsilon>0$, so that (28) is written as

$$
D_{t}=P_{t}-P_{t}^{-\sigma} a_{t}^{\varepsilon}
$$

Substituting (10) and (18) into (29), we see that

$$
D_{t}=p \mathrm{~A} k_{t}-p^{-\sigma}(v \tau)^{\varepsilon} \mathrm{A}^{\varepsilon-\sigma} k_{t}^{\varepsilon-\sigma} .
$$


According to Grossman and Krueger (1995), the environmental Kuznets curve (EKC) arises as a result of countries applying "more stringent environmental standards and stricter enforcement of their environmental laws" (p. 372). From (30), one can establish that there is an inverse U-shaped relationship between $D_{t}$ and $k_{t}$ as long as $\varepsilon-\sigma>1$, which we henceforth assume. Given the presence of the EKC, we impose a nonnegativity constraint on $D_{t}$, i.e., $D_{t}=0 \forall k_{t} \geq \varsigma$, where $\varsigma$ is the solution of the equation $D(k)=0$; that is, $\varsigma \equiv[p \mathrm{~A} / \delta]^{1 /(\varepsilon-\sigma-1)}$, where $\delta \equiv p^{-\sigma} \mathrm{A}^{\varepsilon-\sigma}(v \tau)^{\varepsilon}$.

The second alternative specification is in regard to environmental quality and health status. To avoid the criticism that in reality environmental quality is a stock and not a flow variable, we let health status and life expectancy be functions of environmental degradation. Thus, we replace (2) with

$$
h_{t}=g_{t}^{\varphi} D_{t}^{-\chi}, \varphi, \chi>0 \text {. }
$$

Similarly to the analysis in Sections 2 and 3, a worsening of the natural environment has negative repercussions for the population's health status and life expectancy.

To simplify the technical aspects of the analysis, we employ again the functional form $B\left(h_{t}\right)=\lambda h_{t} /\left(1+h_{t}\right)$. Substituting (1), (9), (11), (30), and (31) into (16), we can express the process of capital accumulation according to

$$
\begin{aligned}
& k_{t+1}=z\left(k_{t}\right)=(1-\tau)(1-\gamma) \\
& \quad \times \mathrm{A} \frac{\lambda\left[(1-v) \tau \mathrm{A} k_{t}\right]^{\varphi}\left[p \mathrm{~A} k_{t}-p^{-\sigma}(v \tau)^{\varepsilon} \mathrm{A}^{\varepsilon-\sigma} k_{t}^{\varepsilon-\sigma}\right]^{-\chi}}{1+(1+\lambda)\left[(1-v) \tau \mathrm{A} k_{t}\right]^{\varphi}\left[p \mathrm{~A} k_{t}-p^{-\sigma}(v \tau)^{\varepsilon} \mathrm{A}^{\varepsilon-\sigma} k_{t}^{\varepsilon-\sigma}\right]^{-\chi}} k_{t},
\end{aligned}
$$

an expression that can be used to examine the implications for economic dynamics under different scenarios concerning the government's stance toward environmental abatement.

We begin the analysis with the case where $v=0$, i.e., there is no pollution abatement. In this case, (32a) can be rewritten as

$$
k_{t+1}=z\left(k_{t}\right)=(1-\tau)(1-\gamma) \mathrm{A} \frac{\lambda \tau^{\varphi} \mathrm{A}^{\varphi-\chi} p^{-\chi} k_{t}^{\varphi-\chi}}{1+(1+\lambda) \tau^{\varphi} \mathrm{A}^{\varphi-\chi} p^{-\chi \chi} k_{t}^{\varphi-\chi}} k_{t} .
$$

\section{PROPOSITION 4.}

(i) If $\varphi>\chi$, then there exists only one positive steady-state equilibrium, which is unstable.

(ii) If $\chi>\varphi$, then there exists again only one positive steady-state equilibrium, which now may be either stable or unstable. If the steady state is stable, then the economy converges either monotonically or with damped oscillations to the unique positive state. On the other hand, if the steady state is unstable, then the economy converges to a limit cycle.

When $\varphi>\chi$, there is a unique positive steady state, which acts as a threshold. Below it the economy will fall into the poverty trap and above it will have a positive growth rate in the long run. These outcomes are not surprising, given that 


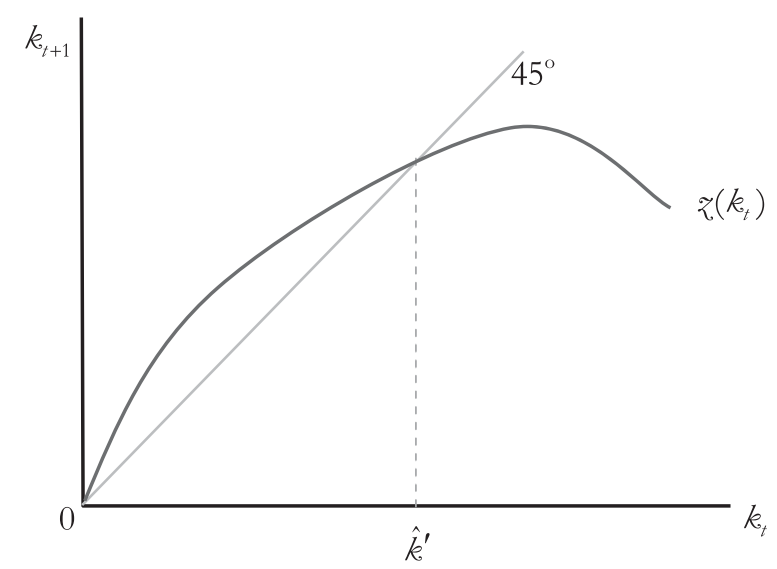

FIGURE 7. $v=0, \chi>\varphi$, and $0<z^{\prime}\left(\hat{k}^{\prime}\right)<1$.

when $\varphi>\chi$ (i.e., when the effect of pollution on life expectancy is not strong enough), the model becomes qualitatively identical to that of Chakraborty (2004), amended with a learning-by-doing externality. On the other hand, if $\chi>\varphi$, then saving is not sufficient enough to guarantee a positive rate of economic growth. Depending on the parameter values, the economy will either converge to a positive level of capital or oscillate permanently between two different levels of capital. Figure 7 illustrates these results. If the steady state lies on the upward-sloping part of $z\left(k_{t}\right)$, then the economy converges monotonically to a positive level of capital stock (such as $\hat{k}^{\prime}$ in Figure 7). If, on the other hand, it lies on the downward-sloping part, then, depending on the magnitude of the slope of $z\left(k_{t}\right)$ in the steady state, the economy either converges to a positive level of capital with damped oscillations or oscillates permanently around an unstable steady state. Obviously, these results and the intuition are similar to those in Section 3.

We examine next the effect of abatement in the scenarios for which, without abatement, the economy cannot sustain an equilibrium with long-run growth and it may be subjected to permanent cycles, i.e., the cases where the negative effect of pollution is sufficiently strong $(\chi>\varphi)$. The transition equation $k_{t+1}=z\left(k_{t}\right)$ is given by (32a) for values of $k_{t}<\varsigma$ and by

$$
k_{t+1}=z\left(k_{t}\right)=(1-\tau)(1-\gamma) \mathrm{A} \frac{\lambda}{(1+\lambda)} k_{t},
$$

for values of $k_{t} \geq \varsigma \cdot{ }^{16}$ Importantly, the map $z(\cdot)$ is continuous. The following proposition then is similar to Proposition 2 in Section 3.

PROPOSITION 5. If $\varphi<\chi$ and $k_{0}$ is sufficiently high, then the economy will converge to a long-run growth equilibrium in which both capital and output per worker grow at the rate $\hat{\theta}=(1-\tau)(1-\gamma) \mathrm{A} \frac{\lambda}{1+\lambda}-1>0$.

Hence, once again pollution abatement acts as a source of long-run growth and (possibly) stabilization. Even under circumstances where, in the absence of 
abatement, the economy cannot sustain a positive growth rate in the long run and can possibly converge to a periodic equilibrium, once pollution abatement becomes active the possibility of limit cycles disappears as capital per worker and output grow over time.

\section{SUMMARY AND CONCLUSIONS}

We have constructed a two-period overlapping-generations model where life expectancy is positively affected by the provision of public health services and by the quality of the natural environment. We showed that, despite the presence of an aggregate learning-by-doing externality, the economy cannot sustain a positive growth rate in the long run if resources are not devoted to environmental preservation. As the environment deteriorates without bound, the negative impact on life expectancy causes a reduction in saving and, therefore, the rate of capital formation: the economy's capital stock either converges to a stationary level or oscillates permanently. An equilibrium with ongoing output growth is possible only if the government commits a sufficient amount of resources to pollution abatement. Given that the possibility of cycles disappears in the latter scenario, we concluded that an active policy of environmental preservation is not only an important complementary engine of long-run growth, but also a powerful tool of stabilization. These results pinpoint the importance of environmentally oriented policies as a means of supporting not only the environment, but also the economy's prospects for sustained economic growth.

Obviously, our framework can be enriched with respect to several aspects that could broaden its scope and implications. For example, an obvious direction is to consider private resources in support of abatement activities, in addition to the public ones. Despite the fact that such an extension generates free riding issues and requires a crucial assumption regarding the degree to which individuals internalize the effect of their own activities on an aggregate outcome such as environmental quality, it would allow us to examine the trade-off between saving and environmental spending. This trade-off would most probably allow an additional channel through which environmental factors impinge on saving and capital accumulation. Moreover, a similar trade-off exists between saving and individual health spending. Finally, when environmental quality is treated as a stock variable, then the externalities associated with environmental outcomes can have significant intergenerational effects; i.e., the extent to which the current generation pollutes may have long-lasting implications for the welfare of future generations. ${ }^{17}$ As long as agents do not possess strongly altruistic characteristics, such a scenario could lie at the core of arguments suggesting that countries do not invest sufficient resources toward environmental improvements. Naturally, there are significant implications for optimal policy under such a setting. ${ }^{18}$ We view these extensions as important topics for future research. 


\section{NOTES}

1. There are a large number of existing theoretical analyses that incorporate endogenous longevity in dynamic general equilibrium models. See, among others, Chakraborty (2004), Bhattacharya and Qiao (2007), and Strulik and Weisdorf (2014).

2. Other analyses of the environment-growth nexus include Prieur and Brechét (2013), Prieur et al. (2013), and Vella et al. (2015).

3. Although life expectancy is higher and mortality rates are lower in more developed countries, this negative relation between income and mortality does not appear to hold for a given country and within shorter intervals. In fact, empirical evidence suggests that mortality rates are procyclical. Such evidence is presented by Ruhm (2000); Chay and Greenstone (2003); and Rolden et al. (2014), among others. What is of particular interest to our analysis is that some of these investigations argue that pollution can be an important explanatory factor for the procyclicality of mortality rates - in the cases of both infant [Chay and Greenstone (2003)] and adult mortality [Rolden et al. (2014)]. In our framework, in the presence of limit cycles, mortality rates co-move with output.

4. Ono (2003) introduces environmental quality in a model of cycles and growth. The implication for environmental policy in his framework is different from that in ours in that he obtains a critical level of tax above which higher growth and improved environmental quality may actually require a less stringent environmental policy, that is, a reduction in abatement efforts.

5. In Smulders and Gradus (1996), pollution declines constantly along the balanced growth path because abatement is sufficiently strong. In one version of our model, abatement can only reduce the rate of environmental degradation. As a result, pollution increases even in the presence of abatement efforts.

6. An agent's expected lifetime at birth is equal to $\beta_{t} 2+1-\beta_{t}=1+\beta_{t}$ periods (recall that she lives 2 periods with probability $\beta$ and 1 with probability $1-\beta$ ). For this reason, we shall be using such terms as "life expectancy," "longevity," and "survival probability" interchangeably. In fact, an alternative interpretation is that in principle all agents survive to the second period, but are alive only a fraction $\beta=\mathrm{B}\left(h_{t}\right) \in[0,1)$ of the period, as, for example, in Bhattacharya and Qiao (2007).

7. Note that health status is a flow and not a stock variable. Although a health stock would be more appropriate in an environment where agents lived for three or more periods, our current assumption seems more suitable in a setting where an agent's potential lifetime is divided into two broad periods. Of course, even in a two-period setting, one can argue that a health stock may make sense once we consider the intergenerational transmission of genetic attributes. Such issues, however, go far beyond the scope of our paper; that is why we have decided to abstract from them.

8. Further support for this idea is provided by Balestra and Dottori (2012), who argue that "it seems reasonable to assume that health expenditure and environmental quality are only imperfect substitutes and exhibit some complementarity to effectively improve health status" (p. 1068).

9. A similar assumption is used in the paper by Clemens and Pittel (2011), namely, $\tilde{p}_{t}=p / a_{t}$. Our functional form has the advantage that it eliminates the possibility of infinite pollution when $\alpha_{t}=0$.

10. In the working paper version of the manuscript we also analyze the case where $e_{t}=$ $e_{t-1}^{\eta}\left(E-P_{t}\right)^{1-\eta}$. Our results remain qualitatively the same.

11. In Appendix A.3, we present an example of an economy with cycles, which illustrates further the results of Proposition 1.

12. By virtue of Assumption $1, \hat{\theta}>0$.

13. Note that $\lim _{k_{t} \rightarrow \infty} e_{t}=\lim _{k_{t} \rightarrow \infty}\left(E-\frac{P_{t}}{1+a_{t}}\right)=\lim _{k_{t} \rightarrow \infty}\left(E-\frac{p \mathrm{~A} k_{t}}{1+v \tau \mathrm{A} k_{t}}\right)=E-\frac{p}{v \tau}>0$, if $\tau>p / v E$.

14. We note that $E$ in John and Pecchenino (1994) is equal to zero. This is so because, in their model, the index of environmental quality is allowed to take negative values. Given the role of environmental quality $(e)$ in our model, we impose that it takes nonnegative values. Moreover, one can easily show that if $E=0$, then Assumption 1 and the assumptions embedded in Lemma 2 and Proposition 3 are all violated.

15. We thank a referee for suggesting these alternative specifications to us. 
16. Upon reaching $k=\varsigma$ (where $D_{t}=0$ ), the agents' health status achieves its maximum possible level. From there on, as long as the government spends enough on pollution abatement to maintain $D_{t}=0$, there is no need to spend resources on health services (more formally, it could just spend an infinitesimal amount). Nevertheless, we assume that the government continues to tax private incomes at a rate $\tau$ and spends the resources over what is needed to maintain $D_{t}=0$ on health services or perhaps on other nonproductive activities. Needless to say, our argument, that pollution abatement is a source of long-run growth, holds all the more in the case where the government reduces the tax rate so that it raises enough resources every period just to maintain $D_{t}=0$.

17. We thank an anonymous referee for suggesting this extension.

18. In the working paper version, we consider the optimal allocation of public spending between direct health expenditures and pollution abatement. Particularly, we examine the choice of $v$ that maximizes the lifetime utility of a representative generation for the model presented in Section 2 . Gutiérrez (2008) provides a formal treatment and analysis of the intergenerational issues.

19. The restriction $\chi \leq \varphi$ is sufficient but not necessary for the results of Lemma 2 and Proposition 2. Effectively, it ensures that only one endogenous threshold separates the two opposite convergence scenarios. In the working paper version, we show that when this assumption is relaxed, it is possible that more equilibria emerge between the poverty trap and the long-run growth equilibrium. Nevertheless, the implication regarding the economy's ability to sustain a positive growth rate in the long run remains intact.

20. An $n$th root of unity, $n=1,2, \ldots$, is a complex number $z$ satisfying the equation $z^{n}=1$.

21. For example, if $p=0.25, \mathrm{~A}=5, \gamma=0.2, \tau=0.1, \chi=5, \varphi=0.3, \lambda=0.95$, then there exists a 2-period cycle $\left(k_{1}, k_{2}\right)=(0.772,0.862)$.

\section{REFERENCES}

Acemoglu, Daron, Philippe Aghion, Leonardo Bursztyn, and David Hemous (2012) The environment and directed technical change. American Economic Review 102, 131-166.

Azariadis, Costas (1993) Intertemporal Macroeconomics. Oxford, UK: Blackwell.

Balestra, Carlotta and Davide Dottori (2012) Aging society, health, and the environment. Journal of Population Economics 25, 1045-1076.

Barnosky, Anthony D., Elizabeth A. Hadly, Jordi Bascompte, Eric L. Berlow, James H. Brown, Mikael Fortelius, Wayne M. Getz, John Harte, Alan Hastings, Pablo A. Marquet, Neo D. Martinez, Arne Mooers, Peter Roopnarine, Geerat Vermeij, John W. Williams, Rosemary Gillespie, Justin Kitzes, Charles Marshall, Nicholas Matzke, David P. Mindell, Eloy Revilla, and Adam B. Smith (2012) Approaching a shift in Earth's biosphere. Nature 486, 52-58.

Bhattacharya, Joydeep and Xue Qiao (2007) Public and private expenditures on health in a growth model. Journal of Economic Dynamics and Control 31, 2519-2535.

Bovenberg, Lans A. and Sjak Smulders (1995) Environmental quality and pollution-augmenting technological change in a two-sector endogenous growth model. Journal of Public Economics 57, 369-391.

Chakraborty, Shankha (2004) Endogenous lifetime and economic growth. Journal of Economic Theory $116,119-137$.

Chay, Kenneth Y. and Michael Greenstone (2003) The impact of air pollution on infant mortality: Evidence from geographic variation in pollution shocks induced by a recession. Quarterly Journal of Economics 118, 1121-1167.

Clemens, Christiane and Karen Pittel (2011) Labor supply and growth effects of environmental policy under technological risk. Macroeconomic Dynamics 15, 31-59.

Devaney, Robert L. (2003) An Introduction to Chaotic Dynamical Systems, 2nd ed. Boulder, CO: Westview Press.

Diamantoudi, Effrosyni and Eftichios S. Sartzetakis (2006) Stable international environmental agreements: An analytical approach. Journal of Public Economic Theory 8, 247-263.

Economides, George and Apostolis Philippopoulos (2008) Growth enhancing policy is a means to sustain the environment. Review of Economic Dynamics 11, 207-219. 
Endres, Alfred and Tim Friehe (2013) The monopolistic polluter under environmental liability law: Incentives for abatement and R\&D. Social Choice and Welfare 40, 753-770.

Grossman, Gene M. and Alan B. Krueger (1995) Economic growth and the environment. Quarterly Journal of Economics 110, 353-377.

Gutiérrez, María-José (2008) Dynamic inefficiency in an overlapping generation economy with pollution and health costs. Journal of Public Economic Theory 10, 563-594.

John, Andrew and Rowena Pecchenino (1994) An overlapping generations model of growth and the environment. Economic Journal 104, 1393-1410.

Jouvet, Pierre-André, Pierre Pestieau, and Gregory Ponthière (2010) Longevity and environmental quality in an OLG model. Journal of Economics 100, 191-216.

Mariani, Fabio, Augustín Pérez-Barahona, and Natacha Raffin (2010) Life expectancy and the environment. Journal of Economic Dynamics and Control 34, 798-815.

Mayer, Helmut (1999) Air pollution in cities. Atmospheric Environment 33, 4029-4039.

Ono, Tetsuo (2003) Environmental tax policy in a model of growth cycles. Economic Theory 22, $141-168$.

Pautrel, Xavier (2008) Reconsidering the impact of the environment on long-run growth when pollution influences health and agents have a finite lifetime. Environmental and Resource Economics 40, 37 52.

Prieur, Fabien and Thierry Brechét (2013) Can education be good for both growth and the environment? Macroeconomic Dynamics 17, 1135-1157.

Prieur, Fabien, Alain Jean-Marie, and Mabel Tidball (2013) Growth and irreversible pollution: Are emission permits a means of avoiding environmental and poverty traps? Macroeconomic Dynamics $17,261-293$.

Requate, Till (2005) Dynamic incentives by environmental policy instruments-A survey. Ecological Economics 54, 175-195.

Rolden, Herbert J.A., David van Bodegom, Wilbert B. van den Hout, and Rudi G.J. Westendorp (2014) Old age mortality and macroeconomic cycles. Journal of Epidemiology and Community Health 68, 44-50.

Romer, Paul (1986) Increasing returns and long-run growth. Journal of Political Economy 5, 10021037.

Ruhm, Christopher J. (2000) Are recessions good for your health? Quarterly Journal of Economics $115,617-650$.

Seegmuller, Thomas and Alban Verchère (2004) Pollution as a source of endogenous fluctuations and periodic welfare inequality in OLG economies. Economics Letters 84, 363-369.

Smulders, Sjak and Raymond Gradus (1996) Pollution abatement and long-term growth. European Journal of Political Economy 12, 505-532.

Stokey, Nancy L. (1998) Are there limits to growth? International Economic Review 39, 1-31.

Strulik, Holger and Jacob Weisdorf (2014) How child costs and survival shaped the Industrial Revolution and the demographic transition. Macroeconomic Dynamics 18, 114-144.

van Zon, Adriaan and Joan Muysken (2001) Health and endogenous growth. Journal of Health Economics 20, 169-185.

Varvarigos, Dimitrios (2014) Endogenous longevity and the joint dynamics of pollution and capital accumulation. Environment and Development Economics 19, 393-416.

Vella, Eugenia, Evangelos V. Dioikitopoulos, and Sarantis Kalyvitis (2015) Green spending reforms, growth, and welfare with endogenous subjective discounting. Macroeconomic Dynamics 19(6), $1240-1260$.

Wang, Min, Jinhua Zhao, and Joydeep Bhattacharya (2015) Optimal health and environmental policies in a pollution-growth nexus. Journal of Environmental Economics and Management 71, 160-179.

Zhang, Junxi (1999) Environmental sustainability, nonlinear dynamics, and chaos. Economic Theory 14, 489-500. 


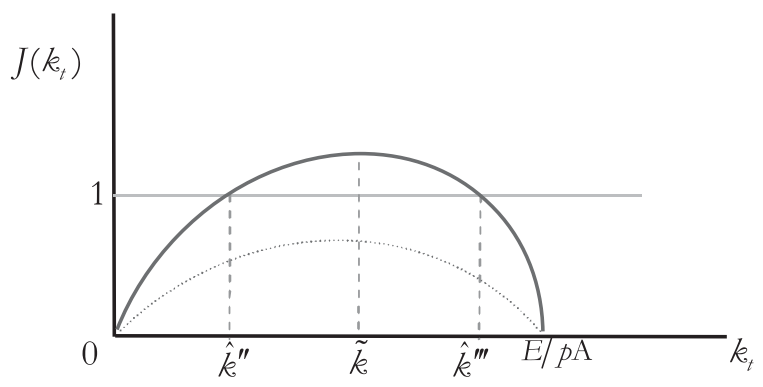

FigURE A.1. The existence of interior steady states requires $J(\tilde{k})>1$.

\section{APPENDIX}

\section{A.1. PROOF OF LEMMA 1}

Using equation (21), we define the function

$$
J\left(k_{t}\right)=\frac{z\left(k_{t}\right)}{k_{t}}=(1-\tau)(1-\gamma) \mathrm{A} \frac{\mathrm{B}\left(\left(\tau \mathrm{A} k_{t}\right)^{\varphi}\left(E-p \mathrm{~A} k_{t}\right)^{\chi}\right)}{1+\mathrm{B}\left(\left(\tau \mathrm{A} k_{t}\right)^{\varphi}\left(E-p \mathrm{~A} k_{t}\right)^{\chi}\right)} .
$$

Clearly, any interior steady state must satisfy $J(\hat{k})=1 \Leftrightarrow \hat{k}=z(\hat{k})$. From (A.1), we have $J(0)=0$ and, by virtue of $(8), J\left(k_{t}\right)=0 \forall k_{t} \geq E / p$ A. Thus, for an interior steady state to exist, there must be at least one $\tilde{k}$ such that $J(\tilde{k}) \geq 1$. When this condition holds with strict inequality, there will be at least two interior steady states; otherwise, there will not be any interior equilibrium at all (see Figure A.1).

Combining (A.1) with (1), (2), (7), (8), and (9) allows us to derive

$$
J^{\prime}\left(k_{t}\right)=(1-\tau)(1-\gamma) \mathrm{A} \frac{\mathrm{B}^{\prime}\left(h_{t}\right)}{\left[1+\mathrm{B}\left(h_{t}\right)\right]^{2}} \frac{d h_{t}}{d k_{t}}
$$

where

$$
\frac{d h_{t}}{d k_{t}}=\varphi \tau \mathrm{A}\left(\tau \mathrm{A} k_{t}\right)^{\varphi-1}\left(E-p \mathrm{~A} k_{t}\right)^{\chi}-p \mathrm{~A} \chi\left(\tau \mathrm{A} k_{t}\right)^{\varphi}\left(E-p \mathrm{~A} k_{t}\right)^{\chi-1} .
$$

For $0 \leq k_{t} \leq E / p \mathrm{~A}$, the sign of (A.3) determines the sign of $J^{\prime}\left(k_{t}\right)$. Straightforward factorization allows us to write (A.3) as

$$
\frac{\partial h_{t}}{\partial k_{t}}=\left(\tau \mathrm{A} k_{t}\right)^{\varphi}\left(E-p \mathrm{~A} k_{t}\right)^{\chi}\left(\frac{\varphi}{k_{t}}-\frac{\chi p \mathrm{~A}}{E-p \mathrm{~A} k_{t}}\right),
$$

which means that $\frac{\partial h_{t}}{\partial k_{t}} \geq 0$ iff

$$
\frac{\varphi}{k_{t}} \geq \frac{\chi p \mathrm{~A}}{E-p \mathrm{~A} k_{t}} \Rightarrow k_{t} \leq \frac{\varphi}{\varphi+\chi} \frac{E}{p \mathrm{~A}} \equiv \tilde{k} .
$$


The preceding analysis implies that there exists a unique $\tilde{k} \in(0, E / p \mathrm{~A})$ such that

$$
J^{\prime}\left(k_{t}\right)\left\{\begin{array}{l}
>0 \text { for } k_{t}<\tilde{k} \\
=0 \text { for } k_{t}=\tilde{k} \\
<0 \text { for } k_{t}>\tilde{k}
\end{array}\right.
$$

i.e., $J(\tilde{k})$ is a global maximum. We can use this result to identify the parameter combination that allows the existence of interior equilibria. Particularly, we can solve $(\tau \mathrm{A} \tilde{k})^{\varphi}(E-p \mathrm{~A} \tilde{k})^{\chi}$ using $\tilde{k}=\varphi E /(\varphi+\chi) p \mathrm{~A}$. Doing so, we derive $(\varphi \tau / p)^{\varphi} \chi^{\chi}[E /(\varphi+\chi)]^{\varphi+\chi} \equiv \Omega$. Hence, by the Intermediate Value Theorem, Assumption 1 is a sufficient condition for the existence of interior equilibria. Moreover, if this condition holds, then there exist two interior steady-state equilibria, $\hat{k}^{\prime \prime \prime}$ and $\hat{k}^{\prime \prime}$, satisfying $\hat{k}^{\prime \prime \prime}>\tilde{k}>\hat{k}^{\prime \prime}>0$; thus, $J^{\prime}\left(\hat{k}^{\prime \prime}\right)>0$ and $J^{\prime}\left(\hat{k}^{\prime \prime \prime}\right)<0$.

Using (A.1), we can derive

$$
J^{\prime}\left(k_{t}\right)=\frac{z^{\prime}\left(k_{t}\right) k_{t}-z\left(k_{t}\right)}{\left(k_{t}\right)^{2}} .
$$

Given (A.4), $J^{\prime}\left(\hat{k}^{\prime \prime}\right)>0$ implies that $z^{\prime}\left(\hat{k}^{\prime \prime}\right)>\frac{z\left(\hat{k}^{\prime \prime}\right)}{\hat{k}^{\prime \prime}} \Rightarrow z^{\prime}\left(\hat{k}^{\prime \prime}\right)>J\left(\hat{k}^{\prime \prime}\right) \Rightarrow z^{\prime}\left(\hat{k}^{\prime \prime}\right)>1$, because $J\left(\hat{k}^{\prime \prime}\right)=1$. Thus, $\hat{k}^{\prime \prime}$ is an unstable equilibrium. Similarly, (A.4) implies that $J^{\prime}\left(\hat{k}^{\prime \prime \prime}\right)<0$ is equivalent to $z^{\prime}\left(\hat{k}^{\prime \prime \prime}\right)<1$. In this case, however, we cannot reach any definite conclusions concerning the stability of this equilibrium, as we do not yet know whether the dynamics generated by (21) is monotonic. For this reason, let us return to the transition equation $k_{t+1}=z\left(k_{t}\right)$. Given (21), we can see that $z(0)=0, z\left(k_{t}\right)=0 \forall k_{t} \geq E / p \mathrm{~A}$, and $z\left(k_{t}\right)>0$ for $k_{t} \in(0, E / p \mathrm{~A})$. Thus, the dynamics of capital accumulation may not be nonmonotonic, which means that, indeed, the stability properties of $\hat{k}^{\prime \prime \prime}$ cannot be determined with certainty. Particularly, $\hat{k}^{\prime \prime \prime}$ is a stable long-run equilibrium if $z^{\prime}\left(\hat{k}^{\prime \prime \prime}\right)>-1$; otherwise, i.e., if $z^{\prime}\left(\hat{k}^{\prime \prime \prime}\right)<-1$, the equilibrium $\hat{k}^{\prime \prime \prime}$ is unstable.

In our preceding analysis, we have established that $z(0)=0$. Of course, this result indicates that $\hat{k}^{\prime}=0$ is a steady state. Moreover, $z^{\prime}\left(k_{t}\right)=J^{\prime}\left(k_{t}\right) k_{t}+J\left(k_{t}\right)$, and because, from (A.2) and (A.3), $\lim _{k \rightarrow 0}\left(\frac{d h_{t}}{d k_{t}} k_{t}\right)=0$ and $J^{\prime}\left(k_{t}\right) k_{t}=0$, it follows that $z^{\prime}\left(\hat{k}^{\prime}\right)=z^{\prime}(0)=0$, i.e., $\hat{k}^{\prime}=0$ is a superstable equilibrium.

\section{A.2. PROOF OF PROPOSITION 1}

Part (i) follows from Lemma 1, in which we have shown that $\hat{k}^{\prime}=0$ is an asymptotically stable equilibrium, whereas $\hat{k}^{\prime \prime}>0$ is an unstable one. Hence, given $\hat{k}^{\prime \prime}>\hat{k}^{\prime}$, we can safely conclude that, for any $k_{0}<\hat{k}^{\prime \prime}, k_{t+1}=z\left(k_{t}\right)<k_{t}$; i.e., the economy's capital per worker will constantly decline until it converges to the poverty trap $\hat{k}^{\prime}=0$.

To prove part (ii), we can once more utilize Lemma 1. In particular, let us consider the case where $\hat{k}^{\prime \prime \prime}$ is an asymptotically stable equilibrium, i.e., the case for which $\left|z^{\prime}\left(\hat{k}^{\prime \prime \prime}\right)\right|<1$. Given $\hat{k}^{\prime \prime \prime}>\hat{k}^{\prime \prime}$, we may conclude that for $k_{0}>\hat{k}^{\prime \prime}$ the transitional dynamics imply that $\lim _{t \rightarrow \infty} k_{t}=\hat{k}^{\prime \prime \prime}$. Also, using (20), we have $\theta_{t+1}=\left(k_{t+1} / k_{t}\right)-1$ and, thus,

$$
\lim _{t \rightarrow \infty} \theta_{t+1}=\lim _{t \rightarrow \infty}\left(\frac{k_{t+1}}{k_{t}}\right)-1=\lim _{t \rightarrow \infty}\left(\frac{z\left(k_{t}\right)}{k_{t}}\right)-1=\lim _{t \rightarrow \infty} J\left(k_{t}\right)-1=J\left(\hat{k}^{\prime \prime \prime}\right)-1=0 .
$$


Therefore, the economy will converge (either monotonically or through damped oscillations) to a long-run equilibrium with a positive stock of capital per worker, but zero growth.

Now, let us consider the possibility that $z^{\prime}\left(\hat{k}^{\prime \prime \prime}\right) \leq-1$. Although $\hat{k}^{\prime \prime \prime}$ is an unstable steadystate equilibrium, it is well known that when the transition equation is nonmonotonic and its slope in the steady state is negative and sufficiently steep (that is, below -1 ), then the dynamical system may exhibit periodic equilibria. In terms of our model, consider a sequence of $n$ discrete points along the $45^{\circ}$ line, denoted $\breve{k}_{\eta}$ for $\eta=\{1,2, \ldots, i-1, i, i+$ $1, \ldots n\}$, such that $\breve{k}_{1}<\ldots<\breve{k}_{i-1}<\breve{k}_{i}<\hat{k}^{\prime \prime \prime}<\breve{k}_{i+1}<\ldots<\breve{k}_{n}$ and

$$
z\left(k_{t}\right)\left\{\begin{array}{lll}
>k_{t} & \text { for } & \eta \in[1, i] \\
<k_{t} & \text { for } & \eta(i, n] .
\end{array}\right.
$$

If, for $k_{0}>\hat{k}^{\prime \prime}$, the capital stock passes repeatedly through the points $\breve{k}_{\eta}$ during its transition, then the economy converges to a period- $n$ cycle, where the sequence $\breve{k}_{\eta}$ represents periodic (rather than stationary) equilibria. Indeed, as long as $z^{\prime}\left(\hat{k}^{\prime \prime \prime}\right)<-1$, the function $z\left(k_{t}\right)$ satisfies the following

THEOREM (Azariadis, 1993, pp. 86-88). Suppose 0 and $\hat{k}>0$ are fixed points of the scalar system $k_{t+1}=z\left(k_{t}\right)$ in which $z: R_{+} \supseteq X \rightarrow R_{+}$and $z \in C^{1}$. Suppose also that there exists $a b>\hat{k}$ such that $b>z(b)$ and $b>z^{2}(b)$, where $z^{2}$ is the second iterate of $z$. Then $z^{\prime}(\hat{k})<-1$ is a sufficient condition for the existence of a period-2 cycle $\left\{\breve{k}_{1}, \breve{k}_{2}\right\}$ that satisfies $\breve{k}_{1}<\hat{k}<\breve{k}_{2}<$ b.

Thus, the system $k_{t+1}=z\left(k_{t}\right)$ exhibits (at least) a period-2 cycle. To apply this theorem to our case, let $\hat{k}=\hat{k}^{\prime \prime \prime}$ and $b=E / p \mathrm{~A}$. Naturally, the growth rate $\theta_{t+1}$ will be positive during phases of the transition for which $\eta \in[1, i]$ but negative during phases of the transition for which $\eta \in(i, n]$. Hence, a long-run equilibrium with a constantly positive growth rate does not exist.

\section{A.3. AN EXAMPLE OF AN ECONOMY WITH CYCLES}

We illustrate the results in Proposition 1 with a simple numerical example. Suppose that

$$
\mathrm{B}\left(h_{t}\right)=\frac{\lambda h_{t}}{1+h_{t}}, 0<\lambda<1 .
$$

This functional form satisfies the properties of $\mathrm{B}(\cdot)$. Let also $\tau=0.2, \gamma=0.3, p=0.3$, $\mathrm{A}=10, E=1, \varphi=0.7$, and $\chi=0.2$. Then at $\lambda=0.682$ a saddle-node bifurcation occurs; that is, the number of fixed points (steady states), except for the origin, is none for $\lambda<0.682$, one for $\lambda=0.682$, and two for values of $\lambda>0.682$. In particular, if $\lambda<0.682$ the origin is the only steady-state equilibrium (Assumption 1 is not satisfied). At $\lambda=0.682$ the function $z\left(k_{t}\right)$ is tangent to the $45^{\circ}$ line and hence there is only one interior steady state. If $\lambda>0.682$ there are two interior steady-state equilibria, say $\hat{k}^{\prime \prime}$ and $\hat{k}^{\prime \prime \prime}$. The lower equilibrium, $\hat{k}^{\prime \prime}$, is repelling, whereas the stability of the higher equilibrium, $\hat{k}^{\prime \prime \prime}$, depends on the value of $\lambda$. For example, if $\lambda=0.7$, then any orbit that starts in the neighborhood of $\hat{k}^{\prime \prime \prime}$ converges to it monotonically, because $0<z^{\prime}\left(\hat{k}^{\prime \prime \prime}\right)<1$. On the other hand, if we let $\lambda=0.75$, then the convergence to $\hat{k}^{\prime \prime \prime}$ occurs through damped oscillations because $0>z^{\prime}\left(\hat{k}^{\prime \prime \prime}\right)>-1$. Next, suppose that we let $\lambda=0.78$. Simple calculations show that the 
stability of the equilibrium $\hat{k}^{\prime \prime \prime}$ changes because $z^{\prime}\left(\hat{k}^{\prime \prime \prime}\right)<-1$; i.e., $\hat{k}^{\prime \prime \prime}$ becomes a repelling equilibrium. At the same time, there is a period- 2 cycle $\{0.306,0.326\}$, which is stable because its multiplier is $z^{2^{\prime}}(0.306)=z^{2^{\prime}}(0.326)=z^{\prime}(0.306) z^{\prime}(0.326)=-0.452>-1$ $\left[z^{2}\right.$ denotes the second iterate of $z$, i.e., $\left.z^{2}\left(k_{t}\right)=z\left(z\left(k_{t}\right)\right)\right]$. Next, suppose that we raise $\lambda$ to 0.8 . Then again simple calculations reveal that, whereas $\hat{k}^{\prime \prime \prime}$ remains a repelling equilibrium, the period- 2 cycle has become an unstable one (the value of its multiplier is lower than $-1)$. Instead, there is a period- 4 cycle now, which is stable. This process continues as $\lambda$ increases. In other words, the system undergoes a sequence of period-doubling bifurcations; that is, there is an increasing sequence of bifurcation points, such that for values of $\lambda$ between any two consecutive members of the sequence, $\lambda_{n}$ and $\lambda_{n+1}$, the prime $2^{n}$ - period solution is stable, whereas the periodic solutions of all other periods $2,4, \ldots, 2^{n-1}$ become unstable.

\section{A.4. PROOF OF LEMMA 2}

Consider again the function

$$
J\left(k_{t}\right)=\frac{z\left(k_{t}\right)}{k_{t}}=(1-\tau)(1-\gamma) \mathrm{A} \frac{\mathrm{B}\left(\left[(1-v) \tau \mathrm{A} k_{t}\right]^{\varphi}\left(E-\frac{p \mathrm{~A} k_{t}}{1+v \tau \mathrm{A} k_{t}}\right)^{\chi}\right)}{1+\mathrm{B}\left(\left[(1-v) \tau \mathrm{A} k_{t}\right]^{\varphi}\left(E-\frac{p \mathrm{~A} k_{t}}{1+v \tau \mathrm{A} k_{t}}\right)^{\chi}\right)} .
$$

Given the properties of $\mathrm{B}\left(h_{t}\right)$ and the restriction $\tau>p / v E$, it can easily be established that $J(0)=0$ and $J(\infty)=(1-\tau)(1-\gamma) \mathrm{A} \lambda /(1+\lambda)$. An interior steady state must satisfy $J(\hat{k})=1 \Rightarrow \hat{k}=z(\hat{k})$. Therefore, Assumption 1 represents a sufficient condition for the existence of an interior equilibrium. This is because $\mathrm{B}(\infty)=\lambda$ and $\mathrm{B}\left(h_{t}\right) /\left[1+\mathrm{B}\left(h_{t}\right)\right]$ is increasing in $h_{t}$; therefore $\lambda>\mathrm{B}(\Omega)$. Differentiating (A.6) yields

$$
J^{\prime}\left(k_{t}\right)=(1-\tau)(1-\gamma) \mathrm{A} \frac{\mathrm{B}^{\prime}\left(h_{t}\right)}{\left[1+\mathrm{B}\left(h_{t}\right)\right]^{2}} \frac{d h_{t}}{d k_{t}}
$$

where

$$
\begin{aligned}
& \frac{d h_{t}}{d k_{t}}=\varphi(1-v) \tau \mathrm{A}\left[(1-v) \tau \mathrm{A} k_{t}\right]^{\varphi-1}\left(E-\frac{p \mathrm{~A} k_{t}}{1+v \tau \mathrm{A} k_{t}}\right)^{\chi} \\
& -\chi\left[(1-v) \tau \mathrm{A} k_{t}\right]^{\varphi}\left(E-\frac{p \mathrm{~A} k_{t}}{1+v \tau \mathrm{A} k_{t}}\right)^{\chi-1} \frac{p \mathrm{~A}}{\left(1+v \tau \mathrm{A} k_{t}\right)^{2}}
\end{aligned}
$$

Substituting (A.7) into the expression for $J^{\prime}\left(k_{t}\right)$ gives us

$$
J^{\prime}\left(k_{t}\right)=\frac{(1-\tau)(1-\gamma) \mathrm{AB}^{\prime}\left(h_{t}\right)}{\left[1+\mathrm{B}\left(h_{t}\right)\right]^{2}}\left[(1-v) \tau \mathrm{A} k_{t}\right]^{\varphi}\left(E-\frac{p \mathrm{~A} k_{t}}{1+v \tau \mathrm{A} k_{t}}\right)^{\chi} \Xi\left(k_{t}\right),
$$

where

$$
\Xi\left(k_{t}\right)=\frac{\varphi}{k_{t}}-\frac{\chi p \mathrm{~A}}{\left(1+v \tau \mathrm{A} k_{t}\right)^{2}} \frac{1}{E-\frac{p \mathrm{~A} k_{t}}{1+v \tau \mathrm{A} k_{t}}} .
$$

Obviously, the sign of $J^{\prime}\left(k_{t}\right)$ depends on the sign of $\Xi\left(k_{t}\right)$ in (A.9). In particular, for this to be non-negative, it must be $\Xi\left(k_{t}\right) \geq 0$. After some algebraic manipulation, the inequality 
$\Xi\left(k_{t}\right) \geq 0$ is reduced to a quadratic expression,

$$
\left(k_{t}\right)^{2}+\frac{(v \tau E-p)+\left(v \tau E-\frac{p \chi}{\varphi}\right)}{(v \tau E-p) v \tau \mathrm{A}} k_{t}+\frac{E}{(v \tau E-p) v \tau \mathrm{A}^{2}} \geq 0 .
$$

As long as $2 v \tau E>p(\varphi+\chi) / \varphi$, which is true if $\tau>p / v E$ and $\chi \leq \varphi$, this expression holds with strict inequality and, by virtue of (A.8) and (A.9), $J^{\prime}\left(k_{t}\right)>0 \forall k_{t}$. Hence, there is only one interior steady state $\hat{k}_{2}$ with $J^{\prime}\left(\hat{k}_{2}\right)>0$. Moreover, it can easily be checked that $J^{\prime}\left(\hat{k}_{2}\right)>0 \Rightarrow z^{\prime}\left(\hat{k}_{2}\right)>1$, i.e., the interior steady state is unstable. ${ }^{19}$

Next, notice from equation (19) that $z(0)=0$; hence, $\hat{k}_{1}=0$ is a steady state. Moreover,

$$
z^{\prime}\left(k_{t}\right)=J^{\prime}\left(k_{t}\right) k_{t}+J\left(k_{t}\right),
$$

and because, from equations (A.8) and (A.9),

$$
\lim _{k \rightarrow 0} \Xi\left(k_{t}\right) k_{t}=0 \text { and } J^{\prime}\left(k_{t}\right) k_{t}=0,
$$

it follows that $z^{\prime}\left(\hat{k}_{1}\right)=z^{\prime}(0)=0$, i.e., $\hat{k}_{1}=0$ is a superstable equilibrium.

\section{A.5. THE DYNAMICS OF ENVIRONMENTAL QUALITY}

The dynamics in $k$ dictates the dynamics in $e$. More specifically, the dynamic behavior of environmental quality $e_{t}$ is described by the contemporaneous equation $e_{t}=E-\frac{p \mathrm{~A} k_{t}}{1+v \tau \mathrm{A} k_{t}}$.

Note that $e_{t}$ is a continuous function of $k_{t}$ and $d e_{t} / d k_{t}<0$. Thus, it follows, from the equation directly preceding, that if $k_{t} \rightarrow k^{*}$, then $e_{t} \rightarrow E-\frac{p \mathrm{~A} k^{*}}{1+v \tau k^{*}}$. In particular, if $k^{*} \rightarrow 0$, then $e^{*} \rightarrow E$, whereas if $k^{*} \rightarrow \infty$, then $e^{*} \rightarrow E-\frac{p}{v \tau}$. On the other hand, if $k$ oscillates between two values, say $\widehat{k}_{1}$ and $\widehat{k}_{2}$, where $\widehat{k}_{2}>\widehat{k}_{1}$, then $e$ oscillates between $\widehat{e}_{1}$ and $\widehat{e}_{2}$, where $\widehat{e}_{1}=E-\frac{p \mathrm{~A} \widehat{k}_{1}}{1+v \tau \mathrm{A} \widehat{k}_{1}}>\widehat{e}_{2}=E-\frac{p \mathrm{~A} \widehat{k}_{2}}{1+v \tau \mathrm{A} \widehat{k}_{2}}$.

\section{A.6. PROOF OF PROPOSITION 2}

Part (i) follows from Lemma 2. Specifically, given that $\hat{k}_{1}=0$ is an asymptotically stable equilibrium and $\hat{k}_{2}>0$ is an unstable one, for any $k_{0}<\hat{k}_{2}$, we have $k_{t+1}<k_{t}$ for all subsequent steps of the transition. Hence, the economy's stock of capital per worker will constantly decline until it reaches the poverty trap $\hat{k}_{1}=0$.

To prove part (ii), we can use (19) and (20) to write the gross growth rate as

$$
\frac{k_{t+1}}{k_{t}}=1+\theta_{t+1}=(1-\tau)(1-\gamma) \mathrm{A} \frac{\mathrm{B}\left(\left[(1-v) \tau \mathrm{A} k_{t}\right]^{\varphi}\left(E-\frac{p \mathrm{~A} k_{t}}{1+v \tau \mathrm{A} k_{t}}\right)^{\chi}\right)}{1+\mathrm{B}\left(\left[(1-v) \tau \mathrm{A} k_{t}\right]^{\varphi}\left(E-\frac{p \mathrm{~A} k_{t}}{1+v \tau \mathrm{A} k_{t}}\right)^{\chi}\right)}
$$

for which Section A.4 establishes that $k_{t+1}>k_{t} \Rightarrow 1+\theta_{t+1}>1$ (as long as $k_{0}>\hat{k}_{2}$ ), because the dynamics of capital accumulation is monotonic. Therefore, (A.11) can be written as

$$
k_{t}=\prod_{\varepsilon=0}^{t}\left(1+\theta_{\varepsilon}\right) k_{0}
$$




\section{4}

From (A.12) we can verify that $\lim _{t \rightarrow \infty} k_{t}=k_{\infty} \rightarrow \infty$. Therefore, we can use (A.11) to establish that

$$
\begin{aligned}
\lim _{t \rightarrow \infty} \theta_{t+1} & =\theta_{\infty} \\
& =\lim _{t \rightarrow \infty}\left[(1-\tau)(1-\gamma) \mathrm{A} \frac{\mathrm{B}\left(\left[(1-v) \tau \mathrm{A} k_{t}\right]^{\varphi}\left(E-\frac{p \mathrm{~A} k_{t}}{1+v \tau \mathrm{A} k_{t}}\right)^{\chi}\right)}{1+\mathrm{B}\left(\left[(1-v) \tau \mathrm{A} k_{t}\right]^{\varphi}\left(E-\frac{p \mathrm{~A} k_{t}}{1+v \tau \mathrm{A} k_{t}}\right)^{\chi}\right)}-1\right] \\
& =(1-\tau)(1-\gamma) \mathrm{A} \frac{\lambda}{1+\lambda}-1=\hat{\theta} .
\end{aligned}
$$

Because $(1-\tau)(1-\gamma) \mathrm{A} \lambda /(1+\lambda)>1$ (from Assumption 1$), \hat{\theta}>0$ : asymptotically, the economy will converge to a balanced growth path where capital per worker grows at a rate $\hat{\theta}$.

\section{A.7. PROOF OF PROPOSITION 3}

If there is no pollution abatement, i.e., $v=0$, the planar system of equations (24) and (25) simplifies to

$$
k_{t+1}=\frac{(1-\tau)(1-\gamma) \lambda \tau \mathrm{A}^{2} k_{t}^{2}\left[(1-\eta) E+\eta m_{t}-p \mathrm{~A} k_{t}\right]}{1+(1+\lambda) \tau \mathrm{A} k_{t}\left[(1-\eta) E+\eta m_{t}-p \mathrm{~A} k_{t}\right]}
$$

and

$$
m_{t+1}=(1-\eta) E+\eta m_{t}-p \mathrm{~A} k_{t} .
$$

As for the steady-state loci, we have

$$
m=\frac{1}{\eta}\left\{\frac{1}{[(1-\tau)(1-\gamma) \mathrm{A} \lambda-(1+\lambda)] \mathrm{A} \tau k}-((1-\eta) E-p \mathrm{~A} k)\right\},
$$

and

$$
m=E-\frac{1}{1-\eta} p \mathrm{~A} k
$$

Combining equations (A.13) and (A.14), we find that the steady-state values of $k$ are the solutions of the quadratic equation

$$
\begin{aligned}
& {[(1-\tau)(1-\gamma) \mathrm{A} \lambda-(1+\lambda)] p \mathrm{~A}^{2} \tau k^{2}} \\
& \quad-[(1-\tau)(1-\gamma) \mathrm{A} \lambda-(1+\lambda)](1-\eta) E \mathrm{~A} \tau k+1-\eta=0 .
\end{aligned}
$$

This equation does not have a real root if $4 p>[(1-\tau)(1-\gamma) \mathrm{A} \lambda-(1+\lambda)](1-$ $\eta) E^{2} \tau$. On the other hand, if $p$ is sufficiently low, it has two positive roots. ii) This follows right away from the limiting properties of equations (26) and (27) (see also Figure 6).

\section{A.8. EXISTENCE OF A LIMIT CYCLE WHEN $e$ IS A STOCK VARIABLE}

If we use the values $\tau=0.4, \gamma=0.4, p=0.3, \mathrm{~A}=25, E=10, v=0.5$, and $\eta=0.8$, there are two steady-state equilibria. For example, if $\lambda=0.4$, then the two equilibria are 
$\left(k_{1}, m_{1}\right)=(0.005,9.827)$ and $\left(k_{2}, m_{2}\right)=(0.262,0.173)$. Moreover, when $\lambda=0.4$, at both equilibria the eigenvalues are real; one of them has modulus greater and the other less one. Thus, both equilibria are saddlepath stable.

Nevertheless, the stability properties of the equilibria change with $\lambda$. In particular, at $\lambda=0.174$ there are also two equilibria: $(0.029,9.829)$ and $(0.238,1.071)$. Evaluated at the second equilibrium, the system has two complex eigenvalues, $0.817 \pm 0.576 i$, which have modulus 1; i.e., the equilibrium is nonhyperbolic. Neither of these eigenvalues is a second, third, or fourth root of unity. ${ }^{20}$ Moreover, the derivative of the modulus of the eigenvalues, evaluated at $\lambda=0.174$, is equal to 1.468 . It follows then from the Hopf Bifurcation Theorem [see Azariadis (1993, Theorem 8.5, p. 100)] that there exists a limit cycle in the neighborhood of the equilibrium for either $\lambda>0.174$ or $\lambda<0.174$. To find out whether the cycle emerges for values of $\lambda$ higher or lower than 0.174 . we need to apply some additional rather technical tests [see Devaney (2003, Theorem 8.8, p. 249)]. Nevertheless, using numerical methods, we can find that the cycle emerges for values of $\lambda>0.174$. For example, if $\lambda=0.4$, then there is a two-period cycle: $(0.202,0.075)$ and $(0.315,0.547)$. Moreover, because the steady-state equilibrium $\left(k_{2}, m_{2}\right)=(0.262,0.173)$ surrounded by the cycle is unstable in the saddlepath sense, it follows that the cycle is attracting. Hence, given that $m_{t+1}=e_{t}$, the economy converges to an equilibrium where it oscillates between $(k, e)=(0.202,0.547)$ and $(k, e)=(0.315,0.075)$. Just as in Section 3 , where $e$ was a flow variable, low (high) capital stock implies low (high) pollution and high (low) environmental quality. Finally, numerical investigations for a wide range of parameter values can show that cycles of higher periodicity may also emerge.

\section{A.9. PROOF OF PROPOSITION 4}

(i) If $\varphi>\chi$, then it follows from (33) that $z(0)=0, z(\infty)=\infty$, and $z^{\prime}\left(k_{t}\right)>0$. In addition, the gross growth rate $J\left(k_{t}\right)=z\left(k_{t}\right) / k_{t}$ exhibits the following properties: $J(0)=0, J(\infty)>1$, by virtue of Assumption 1 , and $J^{\prime}\left(k_{t}\right)>0$. Using then arguments similar to those in the proof of Lemma 1, the result follows.

(ii) In the case where $\chi>\varphi$, we have to distinguish between two cases.

Case 1: $1+\varphi>\chi>\varphi$. Straightforward calculations show that $z(0)=0, z(\infty)=\infty$, and $z^{\prime}\left(k_{t}\right)>0$. Moreover, $J(0)>1$, by virtue of Assumption $1, J(\infty)=0$, and $J^{\prime}\left(k_{t}\right)<0$. Hence, there exists a unique positive steady-state equilibrium, which is stable.

Case 2: $\chi>1+\varphi$. In this case, $z(0)=0, z(\infty)=0$, whereas initially $z^{\prime}\left(k_{t}\right)>0$ and then $z^{\prime}\left(k_{t}\right)<0$. Also, $J(0)>1, J(\infty)=0$ and $J^{\prime}\left(k_{t}\right)<0$. If the $45^{\circ}$ line intersects the phase line $k_{t+1}=z\left(k_{t}\right)$ on the upward-sloping part, then the equilibrium is stable and the economy approaches it monotonically. If the equilibrium lies on the downward-sloping part and $z^{\prime}(k)>-1$, then the economy approaches it with damped oscillations. Finally, if the equilibrium lies on the downward-sloping part of the phase line and $z^{\prime}(k)<-1$, then the equilibrium is unstable. In this case the economy will approach a stable limit cycle. ${ }^{21}$

\section{A.10. PROOF OF PROPOSITION 5}

From (32a) and (32b), the gross growth rate is given by

$$
J\left(k_{t}\right)=\frac{k_{t+!}}{k_{t}}=\frac{z\left(k_{t}\right)}{k_{t}}=\frac{(1-\tau)(1-\gamma) \mathrm{A} \lambda[(1-v) \tau \mathrm{A}]^{\varphi}}{\pi\left(k_{t}\right)+(1+\lambda)[(1-v) \tau \mathrm{A}]^{\varphi}},
$$




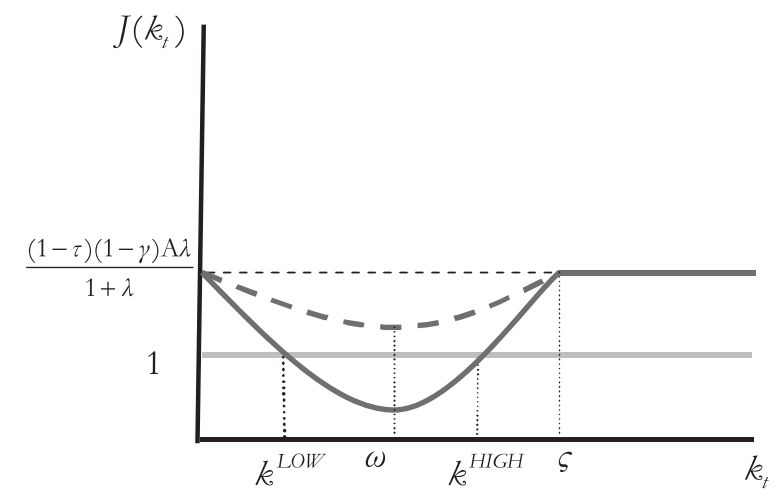

FIGURE A.2. The existence of interior steady states requires $J(\omega)<1$.

if $k_{t}<\varsigma$, where $\pi\left(k_{t}\right)=\left(p \mathrm{~A}-\delta k_{t}^{\varepsilon-\sigma-1}\right)^{\chi} k_{t}^{\chi-\varphi}$ and $\delta \equiv p^{-\sigma}(v \tau)^{\varepsilon} \mathrm{A}^{\varepsilon-\sigma}$, and by

$$
J\left(k_{t}\right)=(1-\tau)(1-\gamma) \mathrm{A} \frac{\lambda}{(1+\lambda)}>1,
$$

if $k_{t} \geq \varsigma$ (recall that $\varsigma \equiv[p \mathrm{~A} / \delta]^{1 /(\varepsilon-\sigma-1)}, \delta \equiv p^{-\sigma} \mathrm{A}^{\varepsilon-\sigma}(v \tau)^{\varepsilon}$, is the solution to the equation $\left.D_{t}=0\right)$. It follows that $J(0)=\frac{(1-\tau)(1-\gamma) \mathrm{A} \lambda}{1+\lambda}>1, J\left(k_{t}\right)=\frac{(1-\tau)(1-\gamma) \mathrm{A} \lambda}{1+\lambda}>1$ $\forall k_{t} \geq \varsigma$.

Moreover, $J^{\prime}\left(k_{t}\right)=-\frac{(1-\tau)(1-\gamma) \mathrm{A} \lambda[(1-v) \tau \mathrm{A}]^{\varphi}}{\left\{\pi\left(k_{t}\right)+(1+\lambda)[(1-v) \tau \mathrm{A}]^{\varphi}\right\}^{2}} \pi^{\prime}\left(k_{t}\right) \forall k_{t}<\varsigma$ and $J^{\prime}\left(k_{t}\right)=0 \forall k_{t} \geq \varsigma$, where $\pi^{\prime}\left(k_{t}\right)=\left(p \mathrm{~A}-\delta k_{t}^{\varepsilon-\sigma-1}\right)^{\chi-1} k_{t}^{\chi-\varphi-1}\left\{(\chi-\varphi) p \mathrm{~A}-[\chi(\varepsilon-\sigma)-\varphi] \delta k_{t}^{\varepsilon-\sigma-1}\right\}$. Let $\omega \equiv\{(\chi-\varphi) p \mathrm{~A} /[(\chi(\varepsilon-\sigma)-\varphi) \delta]\}^{1 /(\varepsilon-\sigma-1)}$. Note that $\omega<\varsigma$. Hence, $\pi^{\prime}\left(k_{t}\right)>0$ and $J^{\prime}\left(k_{t}\right)<0 \forall k_{t} \in(0, \omega), \pi^{\prime}\left(k_{t}\right)<0$ and $J^{\prime}\left(k_{t}\right)>0 \forall k_{t} \in(\omega, \varsigma)$, and $\pi^{\prime}\left(k_{t}\right)=J^{\prime}\left(k_{t}\right)=0$ $\forall k_{t} \geq \varsigma$.

Given the previous analysis, we can distinguish between two possible scenarios regarding the economy's dynamics and long-run equilibrium. First, consider the case where $\frac{(1-\tau)(1-\gamma) \mathrm{A} \lambda\left[(1-v) \tau \mathrm{A} \varphi^{\varphi}\right.}{\bar{\pi}+(1+\lambda)[(1-v) \tau \mathrm{A}]^{\varphi}}>1, \bar{\pi} \equiv \pi(\omega)$. If this condition holds, then $J\left(k_{t}\right)=\frac{k_{t+1}}{k_{t}}>1$ $\forall k_{t}$, i.e., the economy will grow at positive rates (see Figure A.2). The second possibility regarding the economy's dynamics is that $\frac{(1-\tau)(1-\gamma) \mathrm{A} \lambda\left[(1-v) \tau \mathrm{A} \varphi^{\varphi}\right.}{\bar{\pi}+(1+\lambda)[(1-v) \tau \mathrm{A}\}^{\varphi}}<1$. Taking account of previous results, we have two steady-state solutions, say $k^{\mathrm{LOW}}$ and $k^{\mathrm{HIGH}}\left(k^{\mathrm{LOW}}<k^{\mathrm{HIGH}}\right)$, such that $J\left(k^{\mathrm{LOW}}\right)=J\left(k^{\mathrm{HIGH}}\right)=1, J^{\prime}\left(k^{\mathrm{LOW}}\right)<0$, and $J^{\prime}\left(k^{\mathrm{HIGH}}\right)>0$. In this case, $k^{\mathrm{HIGH}}$ emerges as a threshold above which the economy will grow at positive rates in the long run: once more, pollution abatement acts as a source of long-run growth and stabilization in economies for which $k_{0}>k^{\mathrm{HIGH}}$. 